\title{
Level 4: Games! ;-)
}

Kommen wir nun zu dem zentralen Thema des Buches: den Games. Manche Leser mögen nun denken: „Na endlich geht's los mit Gaming in Bibliotheken“ aber nach diesem Kapitel werden Sie wahrscheinlich feststellen, dass auch das Thema Games viel komplexer ist, als man es eigentlich erwarten würde. Denjenigen von Ihnen, die vor allem wissen wollen, welche Games sie in den Bestand aufnehmen sollten, empfehle ich zuerst das anschließende Kapitel „Bestandsfragen“ zu lesen. Wenn Sie dann noch Lust haben, mehr über die Games zu erfahren, können Sie sich mit diesem Kapitel befassen.

Grundsätzlich werde ich in diesem Kapitel nicht unterscheiden zwischen Spielen, die eine Bibliothek in den Bestand aufnehmen kann und solchen, die sich dafür nicht eignen. Ich werde auch nicht darauf achten, nur die Spiele zu beschreiben die aufgrund Ihrer Altersfreigabe Bibliotheks-kompatibel sind. Das würde schlichtweg sinnlos sein. Die meisten Spiele sind nicht ohne weiteres kompatibel zu einer Bibliothek. Dies hat z.B. technische Gründe, wenn also Spiele nicht in den Bestand aufgenommen werden können, weil sie digital vertrieben werden oder weil Bibliotheken keinen Zugriff auf die Vertriebsplattformen haben oder weil die Spiele online gespielt werden. Es hat aber auch rechtliche Gründe, wenn das jeweilige Spiel beispielsweise keine Altersfreigabe hat, die eine Nutzung in der Bibliothek erlaubt.

Ich sehe Gaming aber nur sekundär als Bestandsthema und wenn Sie als Bibliotheksmitarbeiter Gaming in die Bibliothek bringen möchten, dann brauchen Sie ein möglichst breites Basiswissen zu diesem Thema. Das bedeutet, dass Sie auch ein bisschen von dem wissen sollten, was sie vielleicht nicht in einer Bibliothek in Sachen Gaming erleben können. Nur so bekommen Sie ein Gefühl für das, was Menschen wie ich die „Gaming-Kultur“ nennen und nur so sind Sie in der Lage, mit den Menschen auf Augenhöhe zu diskutieren, die Gaming noch immer für das Böse schlechthin halten. Denken Sie immer daran: in anderen Themengebieten haben Bibliotheken über die Jahre und Jahrzehnte Know-How aufbauen können. Im Bereich Gaming stehen die meisten Bibliotheken noch am Anfang.

In diesem Level werden Sie viele verschiedenen Games kennenlernen. Nicht alle von ihnen sind digital oder werden auf Konsolen gespielt. Sie werden auch Mischformen kennenlernen und in Teilen wird es um Inhalte gehen, bei denen es nur noch um die Adaption bzw. Implementierung von Gaming-Elementen in andere Kontexte geht. Dieses Level ist mit Sicherheit nicht vollständig. Ich habe für Sie eine Vorauswahl getroffen. Das Ziel ist, dass Sie die Komplexität und die Besonderheiten der GamingKultur verstehen. Die Daten aus diesem Level eignen sich also nicht, um z. B. Games $\mathrm{zu}$ verschlagworten oder zu strukturieren, und dies ist auch nicht die Aufgabe von Bibliotheken - zumindest nicht bei diesem Thema.

Natürlich habe ich auch eine kleine Struktur entworfen. In einem ersten Schritt werde ich auf die Games eingehen, die man klassisch als Computergames bezeichnen würde. Dazu gehören sowohl alte als auch zum jetzigen Zeitpunkt aktuelle Spiele. In den letzten Jahren hat sich die Gamingwelt nachhaltig verändert. Neue Arten von Games sind hinzugekommen und andere wurden verdrängt. Auch diese Veränderungen werde ich beschreiben. Bei der Recherche für dieses Buch ist mir klar geworden, dass das Level zu Games ein Bereich des Buches ist, der gut und gerne vierhundert Seiten füllen könnte. Zudem haben wir es letztlich nicht mit einer linearen Entwicklung in einem abgeschlossenen Raum zu tun. Ich beschreibe also einzelne kleine Steine eines Mosaiks und hoffe, dass ich die Verbindungen zwischen den Steinen und das daraus resultierende Gesamtbild schlüssig entwickeln kann. Wie bereits erwähnt: dieses Level hat nicht den Anspruch auf Vollständigkeit. Ich habe die Inhalte 
ausgewählt, die Sie meiner Meinung nach verstehen und kennenlernen sollten, um das Thema in Ihrer Bibliothek erfolgreich umsetzen zu können. Aber auch wenn ich versuche, Ihnen möglichst alle wichtigen Informationen zur Verfügung zu stellen. Sie werden früher oder später mit dem Ausprobieren verschiedener Games beginnen müssen. Nur so können Sie wirklich „verstehen“ warum so viele Menschen Gefallen an dem Thema finden.

Bevor es nun losgeht noch ein wichtiger Hinweis: Die Grenzen zwischen den einzelnen Genres sind fließend. Es gibt keine allgemein gültige Definition. Dies liegt auch daran, dass immer neue Formate entstehen. Es gibt auch Spiele, die sich verschiedenen Formaten zuordnen lassen. Ich habe deshalb entschieden, in einigen Fällen eigene Definitionen zu entwickeln und/oder Genres zusammen zu fassen.

Neben den eigentlichen Games möchte ich in diesem Level auch auf Anwendungen eingehen, die nur Gaming-Elemente nutzen. Schließlich beschreibe ich auch neue Modelle, wie „Alternate Reality Games“ oder „Augmented Reality Games“ bzw. die Idee von „Gamification“ als Ganzes.

In der täglichen Arbeit ist es in den meisten Fällen so, dass nur ganz bestimmte Definitionen genutzt werden. D. h. Sie sollten wissen was ein Shooter, ein Adventure, eine Simulation, ein Rollenspiel etc. ist. Sie sollten auch in der Lage sein, zwischen Offline- und Online-Games zu entscheiden. Wie bereits des Öfteren erwähnt, müssen Sie nicht alle diese einzelnen Definitionen auswendig lernen. Wenn Sie wirklich im Bereich Gaming aktiv sein möchten, werden Sie nicht umhin kommen, sich kontinuierlich mit dem Thema zu beschäftigen. Dazu gehört auch das Lesen von Fachmagazinen und natürlich von Blogs und Facebook-Seiten. Auf diesem Weg werden Sie früher oder später die einzelnen Definitionen und, was noch viel wichtiger ist, die Bedeutung und die Zusammenhänge verinnerlicht und verstanden haben. Auch ich lerne täglich weiter und bin alles andere als allwissend im Bereich Gaming. Als Bibliothek müssen Sie auch nicht allwissend sein, aber Sie müssen die Bereitschaft haben, kontinuierlich zu lernen, sich mit Anderen zu vernetzen und natürlich Fehler zu machen. Wenn Sie diesen Rat beherzigen, werden Sie sehr schnell über ein fundiertes Wissen in diesem Bereich verfügen.

Konzentrieren Sie sich auf keinen Fall nur auf die Gaming-Themen die Ihnen zusagen bzw. die Sie in Ihrer Bibliothek nutzen können. Natürlich ist es so, dass Sie z. B. aus Gründen der Jugendschutzes (Altersfreigaben) oder der Vertriebsvariante (z.B. Online-Games) einige spannende Gaming-Themen wirklich nicht bearbeiten können. Aber es ist wichtig, dass Sie die Zusammenhänge der Gaming-Kultur verstehen. Zudem können Sie auch von diesen Bereichen lernen und manchen Ansatz in anderen Bereichen der Bibilotheksarbeit anwenden.

\section{Genres - Computergames}

\section{Shooter}

Wenn man sich mit den verschiedenen Genres der Gaming-Welt beschäftigt, kommt man an den Shootern nicht vorbei. Wahrscheinlich werden Sie mit diesem Genre nur in Ausnahmefällen arbeiten können, da die meisten dieser Spiele eine Altersfreigabe USK16 oder USK18 haben. Und das Thema Shooter ist zudem eines der am umstrittensten Themen überhaupt. Um die Gründe dafür zu verstehen müssen wir zuerst klären, was mit dem Begriff gemeint ist.

In Shootern geht, wie der Name schon sagt um Schießen. Und bis auf ein paar Ausnahmen wird dabei auf virtuelle Gegner bzw. Avatare von anderen realen Spielern 


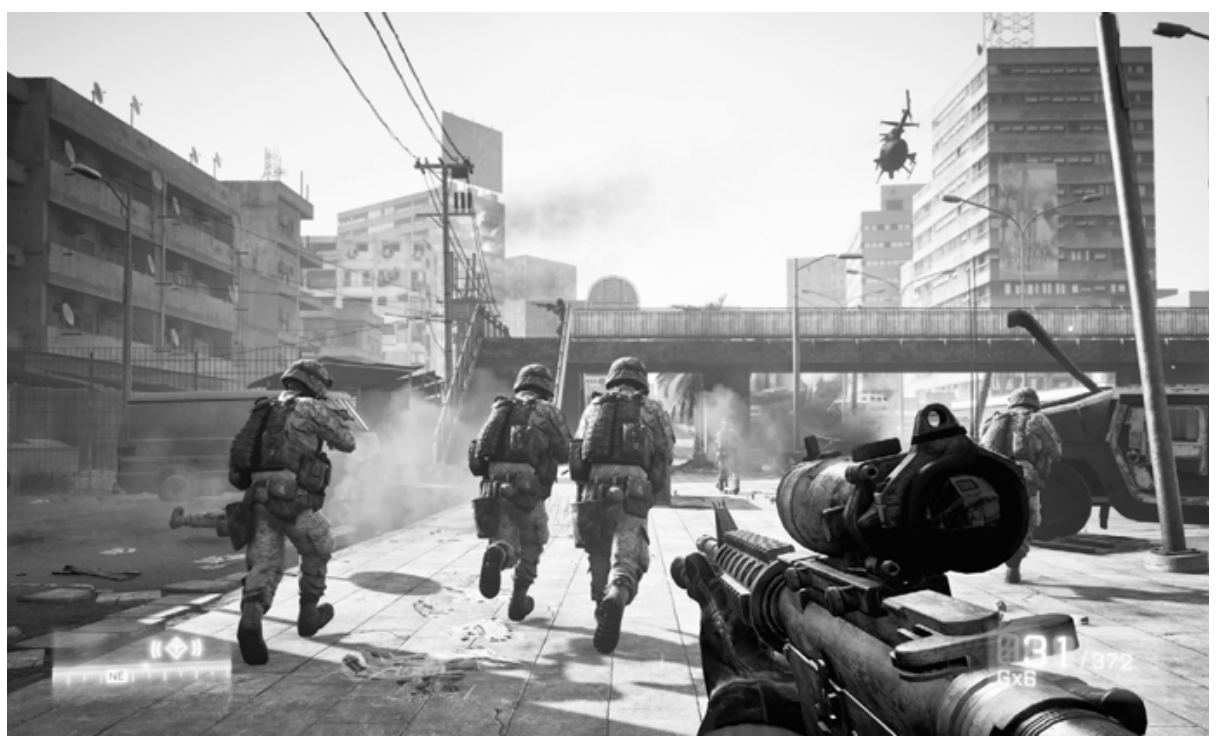

Abb. 11 Screenshot aus dem Shooter Battlefield 3 von Electronic Arts. Mit freundlicher Genehmigung von Electronic Arts.

geschossen. Das Grundmodell ist verhältnismäßig einfach. Der Spieler bewegt sich durch eine künstliche dreidimensionale Welt. Er ist mit einer oder mehreren Waffen, sowie in manchen Fällen weiteren hilfreichen Gegenständen versorgt. Die Aufgabe ist nun, sich in der dreidimensionalen Welt zu bewegen und die „Gegner“ zu zerstören oder zu erschießen. Es gibt eine Vielzahl an verschiedenen Shooterformen. Die bis heute bekanntesten Shooter sind u.a. DOOM, Wolfenstein, Counter Strike, Battlefield, Call of Duty.

Das grundsätzliche Modell ist bis heute erhalten geblieben. Allerdings gibt es heute verschiedene Varianten. Am bekanntesten sind sicherlich die sogenannten First-Person-Shooter, die im deutschen Sprachraum auch „Ego-Shooter“ genannt werden. Bei dieser Form sieht man die Welt aus der Sicht der Spielfigur. In der Regel sieht man auch die jeweilige Waffe, mit der man aktuell kämpft. Eine andere Variante sind die sogenannten Third-Person-Shooter, bei der man das Geschehen aus Sicht einer fiktiven dritten Person wahrnimmt. Hierzu gehören Shooter wie „Max Payne“, „Dead Space“ oder „Just Cause“. Im Laufe der Jahre haben sich Shooter in vielen Bereichen weiterentwickelt. Da ist zum einen die Grafik. Diese wird kontinuierlich besser, was bedeutet detaillierter. Dabei gibt es, wie bei vielen anderen Genres auch letztlich zwei Ziele: Entweder sollen die Spiele so realitätsnah wie möglich sein. Oder aber man möchte die virtuelle Welt so darstellen, dass der Spieler sie als möglichst realistisch wahrnimmt. Dieser Entwicklung führte gerade bei Shootern immer wieder zu heftigsten Diskussionen, da daraus resultierend auch Gewaltdarstellungen sehr detailliert und realitätsnah dargestellt werden können. Aus diesem Grund werden einige Shooter mit einer Altersfreigabe nur für Erwachsene versehen. Es gibt aber auch Shooter, die verschiedene Versionen haben, sodass auch jüngere Spieler - in der Regel ab 16 Jahre - diese Spiele spielen können. Und natürlich gibt es auch einige wenige Shooter mit einer Altersfreigabe ab 12 Jahren.

Die Aufgaben und Zielrichtungen in den Spielen haben sich auch weiterentwickelt. Einige Shooter haben einen höheren Anteil bzw. ein tiefer gehendes Storytelling. Andere haben sehr viel mit Taktik zu tun. So gibt es in manchen Shootern verschiedene Waffen mit verschiedenen Vor- und Nachteilen. Diese ergeben sich aus der Anzahl der möglichen Einsätze, der Reichweite, der Wirkung etc. Der Spieler muss 


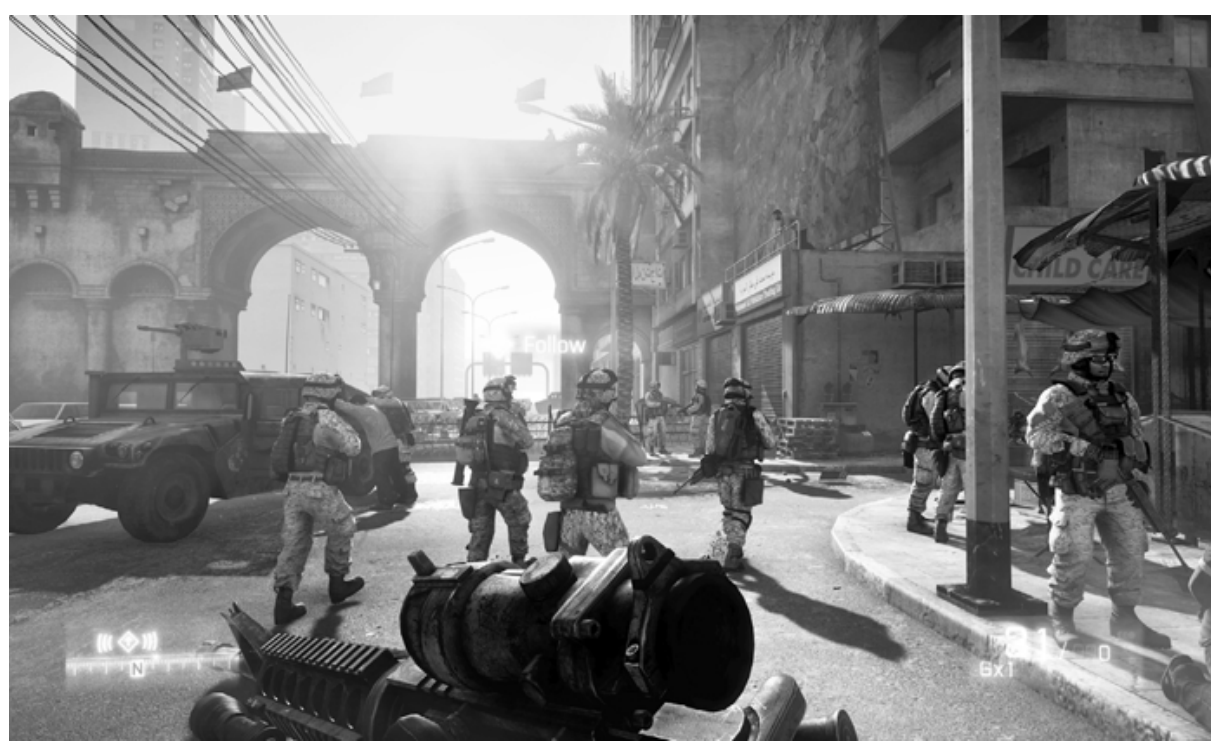

Abb. 12 Screenshot aus dem Shooter Battlefield 3 von Electronic Arts. Mit freundlicher Genehmigung von Electronic Arts.

nun situationsabhängig überlegen, welche Waffe er für welche Situation benötigt bzw. nutzen möchte. Dies wird vor allem dann interessant, wenn er das Spiel mit Anderen spielt. In anderen Shootern gibt es bestimmte Formen von Gegnern und eine bestimmte Umwelt, auf die Spieler mit eigenen Taktiken hinsichtlich, Strategie des Angriffs, Auswahl der Waffen, Abfolge der einzelnen Schritte, Anpassung an die Umwelt-Gegebenheiten etc. reagieren müssen. Dies erfordert ein kontinuierliches Lernen und Ausprobieren. Zudem müssen ebenfalls kontinuierlich Informationen gesammelt, bewertet und gespeichert werden.

Ein besonderes Highlight für die meisten Spieler sind aber die sogenannten Multiplayer-Spiele. Das Modell ist dabei verhältnismäßig einfach. Der Spieler loggt sich auf einen Server ein, auf dem eine oder mehrere Karten liegen. Diese Karten bzw. englisch „Maps“ bilden quasi das Spielfeld für den Wettkampf. Es können sich nun verschiedene Spieler auf den Karten einloggen. Irgendwann beginnt das Spiel und die die Spieler treten in Teams gegeneinander an. Die Aufgaben können vielfältig sein. So kann es darum gehen, einfach so viele Gegner wie möglich zu besiegen und dabei selber nicht zu verlieren. Es kann auch darum gehen, ein bestimmtes Gebiet gegen Angreifer zu verteidigen usw. Wenn ein Spieler im Spiel stirbt, wird er in der Regel nach kurzer Zeit wieder reanimiert und kann weiter spielen. Die Teams nennt man auch „Squads“ oder „Clans“. In vielen Shootern ist der Zugang zu MultiplayerKarten bereits implementiert. Der Spieler kann sich also einfach irgendwo einloggen. Auf manchen Karten gibt es Restriktionen. So dürfen beispielsweise bestimmte Waffen nicht benutzt werden oder aber die Zeit bis zur „Auferstehung“ nach dem man getötet wurde ist länger. In manchen Fällen wird man auch von der Karte entfernt, weil die eigene Spielstärke zu schwach ist. Viele Spieler möchten gegen gleichstarke Spieler antreten. Zu starke oder zu schwache Gegner sorgen schnell für Frust oder Langeweile.

Im Bereich der Shooter ist noch wichtig zu erwähnen, dass einige Spieler mit Absicht, die Grafikauslösung verringern, weil sie sich damit einen Geschwindigkeitsvorteil erhoffen. In Shootern geht es zumeist um Millisekunden. Eine Grafikkarte, die Bilder in hoher Auflösung berechnen muss, braucht u.U. einige Millisekunden länger. Es geht also gerade im Bereich Multiplayer nicht um die Darstellung von Gewalt sondern 


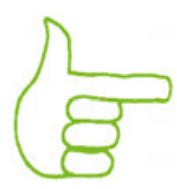

um den Wettbewerb. In einigen Shootern, die ihren Fokus auf den Bereich Multiplayer legen, sind die sogenannten Einzelspieler-Kampagnen sehr schwach. Diese Kampagnen spielt man alleine gegen den Computer. Dabei wird eine Geschichte erzählt, in deren Verlauf es immer wieder zu Gefechten kommt.

Besonders erfolgreich war das Spiel „Counter-Strike“, welches ein reines Multiplayer-Spiel ist. Sehr viele Spieler haben sich hier zu „Clans“ zusammengeschlossen und diese Clans trainieren zusammen und treten gemeinsam in Wettbewerben an.

Shooter haben auch andere Spielgenres beeinflusst. Vor allem die Darstellung in der First-Person-Perspektive können wir auch in anderen Spielen beobachten, in denen es um ganz andere Aufgaben bzw. Inhalte geht.

Entgegen der medialen Wahrnehmung bzw. Darstellung, sind Shooter nicht die erfolgreichsten Spiele im Gaming-Universum. Allerdings sind die Produktionskosten in den letzten Jahren kontinuierlich gestiegen. So kosten manche Spiele mehr als 140.000.000 \$ und sind damit so teuer wie mancher Hollywoodfilm.

Genre: Shooter

Beschreibung: Ziel der Spiele ist es, den oder die Gegner mittels verschiedener Waffen zu besiegen bzw. auszuschalten. Es gibt First-Person-Shooter bei denen der Spieler das Spiel aus der Sicht des Schützen erlebt und Third-Person-Shooter, bei denen der Spieler das Geschehen aus Sicht einer dritten Person wahrnimmt. Die Spiele werden entweder im Single-Player-Modus oder aber im Multiplayer-Modus gespielt.

Beispiele: Die Battlefield-Reihe, die Crysis-Reihe, Counterstrike, Halo

Voraussetzungen: PC oder Konsole oder Mobile Device

\section{Point and Click}

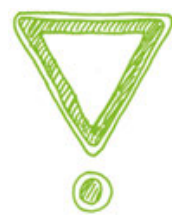

Mit „Point and Click“ ist eine Spielform gemeint, bei der man auf verschiedene Gegenstände und Personen mit der Maus „klickt“ um mit ihnen zu interagieren. Das Auswählen und Bearbeiten der einzelnen Gegenstände erinnert stark an die „normale“ Arbeit mit dem Computer, bei dem auch einzelne Dateien angeklickt werden, um dann mit ihnen zu arbeiten. Diese Arbeitsweise eignet sich auch sehr gut um mehrere Gegenstände oder Einheiten auszuwählen. Point and Click wird in unterschiedlichen Spielvariationen angewendet. Es gibt Adventure-Games die au Point-and-Click basieren. Des Weiteren wird diese Arbeitsweise auch in Strategie- und Rollenspielen wie z. B. „World of Warcraft“ oder „Starcraft“ benutzt.

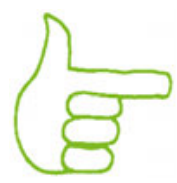

Genre: Point and Click

Beschreibung: Spiele bei denen ich mit dem Cursor auf Gegenstände und Personen klicke um eine Interaktion zu starten

Beispiele: Machinarium, Mass Effect 1-3, Warcraft, Command \& Conquer Voraussetzungen: PC oder Konsole oder Mobile Device

\section{Jump and Run}

„Jump and Run“ beschreibt eine Spielform, bei der man, wie der Name schon sagt, mit seiner Spielfigur andauernd springen und laufen muss. Vor allem das geschickte Springen von Ort zu Ort ist ein relevantes Element des Spiels. Das Spiel kann dabei zwei- und dreidimensional oder auch diagonal dargestellt werden. Jump and RunGames sind sehr weit verbreitet und ein paar der bekanntesten Spiele wie z.B. Super 
Mario oder Donkey Kong sind diesem Genre zuzuordnen. Aktuell werden vor allem durch kleine Studios oder einzelne Entwickler zum Teil hervorragende Jump and Run-Games entwickelt.

Genre: Jump and Run

Beschreibung: Spiele bei denen man sich durch Laufen und Springen durch die Spielewelt bewegt.

Beispiele: Super Mario, Donkey Kong, Limbo, Yo Frankie

Voraussetzungen: PC oder Konsole oder Mobile Device

\section{Maze oder auch Labyrinth-Spiele}

Dieses Genre ist nur noch selten zu finden, Dabei hat das Genre mit „Pacman“ einen weltberühmten Vertreter vorzuweisen. Das Spielmodell ist verhältnismäßig einfach: Man bewegt sich durch ein Labyrinth und muss Gegner finden oder vor ihnen fliehen, man muss Gegenstände einsammeln und die ein oder andere Zusatzaufgabe erfüllen. Warum dieses Genre in den letzten Jahren so massiv an Bedeutung verloren hat, kann ich ehrlich gesagt nicht nachvollziehen. Allerdings gibt es noch immer Spiele, bei denen man sich durch ein Labyrinth bewegen muss. Dieses Labyrinth wird aber anders dargestellt.

Genre: Maze oder auch Labyrinth-Spiele

Beschreibung: Spiele bei denen man sich durch ein Labyrinth bewegt und dabei verschiedene Aufgaben zu erfüllen hat.

Beispiele: Pac Man, Boulder Dash

Voraussetzungen: PC oder Konsole oder Mobile Device

\section{Shoot'em up}

Willkommen in der Welt der Ballerspiele. Dieses Genre ist ebenfalls schon sehr alt. In diesen Spielen geht es darum, mit einer oder mehrerer Waffen so viele Gegner wie möglich auszuschalten. Dies findet in der Regel zweidimensional statt. Der Klassiker ist sicherlich „Space Invaders“. Dieses Spiel wurde in vielen Spielhallen als Automatenversion gespielt und zudem im dritten Teil der Spielfilmreihe „Zurück in die Zukunft“ persifliert. Shot'em up-Games sind keine Spiele, bei denen es um die detaillierte Darstellung von Zerstörung geht. Man steuert ein Gefährt mit verschiedenen unendlich verfügbaren Waffen und schießt so schnell man kann. Dabei bewegt man das Gefährt so, dass man möglichst viele Gegner trifft und dabei selbst unbeschadet davonkommt. Dieses Genre ist auch dafür bekannt, am Ende eines jeden Levels einen sogenannten „Endgegner“ zu haben. Dieser Gegner ist besonders stark und besonders schwer zu zerstören.

Genre: Shoot'em up

Beschreibung: Ballerspiele bei denen ich mit zumeist unendlich zur Verfügung stehenden Waffen möglichst viele Gegner zerstöre ohne selbst zerstört zu werden.

Beispiele: Space Invaders, 1942, Strike Force

Voraussetzungen: PC oder Konsole oder Mobile Device
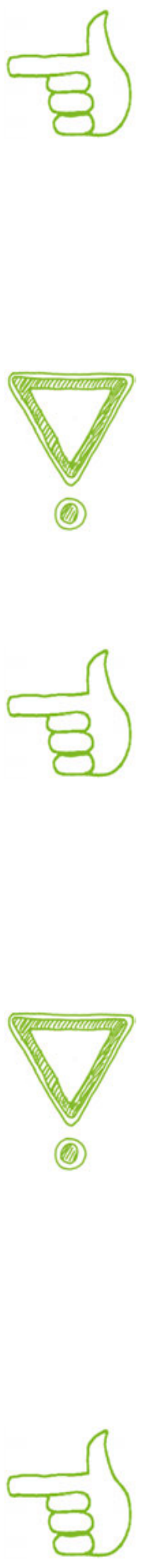


\section{Bewegungs- und Tanzspiele}

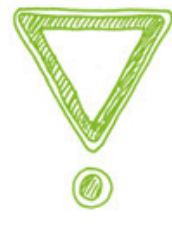

Bewegungs- und Tanzspiele erfreuen sich ebenfalls immer größerer Beliebtheit. Dabei gibt es ebenfalls einige Unterschiede. Vor allem in Japan und Korea aber ebenso in allen anderen Ländern, in denen es noch große Spielhallen gibt, kann man große Automaten finden, bei denen der Spieler auf einer Platte steht, die mit verschiedenen farbigen Sensoren ausgerüstet ist. Der Spieler schaut auf einen Bildschirm auf dem die jeweiligen Schritte durch aufleuchten der Sensoren und/oder eine Figur, die die Abläufe vortanzt, angezeigt werden. Der Spieler hört dabei Musik und kann auf dem Bildschirm im Takt die Schrittfolgen passend zu Musik sehen. Dabei werden sowohl die aktuellen als auch die anstehenden Schritte im Takt angezeigt. Diese Spiele beginnen sehr einfach. In kurzer Zeit steigt aber der Schwierigkeitsgrad immens. Einige Spieler sind in der Lage, selbst komplizierte Bewegungsabläufe in höchster Geschwindigkeit umzusetzen.

Nun muss man aber nicht mehr in eine Spielhalle gehen, um sich spielerisch zu bewegen. Heute gibt es eine Vielzahl an Spielen für stationäre Konsolen, die letztlich auf die gleiche Art und Weise funktionieren. Die Übertragung der Schritte erfolgt entweder über eine Matte mit Sensoren oder aber über eine Kamera wie beim KinectSystem der XBOX360. Besonders beliebt sind dabei Tanz- und Sportspiele. Allerdings stellt sich die Frage, ob letztlich nicht alle Spiele für die XBOX 360 mit dem KinectSystem Bewegungsspiele sind?

Bewegungsspiele vor allem mit dem Kinectsystem der XBOX360 sind für Bibliotheken hoch interessant. Dies hat viele Gründe. Zum einen sind diese Spiele sehr oft für die ganze Familie gedacht. Das bedeutet, dass sie keine problematischen Altersbeschränkungen haben. Die Bibliothek hat also keine Probleme, an neue spannende Spiele zu kommen bzw. diese in der Öffentlichkeit spielen zu lassen. Zum anderen sind Bewegungsspiele etwas, was in den Raum bzw. den Ort der Bibliothek hineinwirkt. Dies geschieht u. a. auf folgende Art und Weise:

- Die Spieler bewegen sich vor den Konsolen. Der eigene Körper ist der Controller. Es gibt also Bewegung im Raum

- Das Zuschauen macht größeren Spaß, da der Zuschauer nicht nur das Spiel sondern ebenso die Bewegungen des Spielers beobachten kann.

- Die Teilnehmer erleben somit Gaming als Bewegung und nicht als stillsitzen. Dies macht das Aktivieren anderer Bibliotheksbesucher einfacher.

Zudem sind Bewegungsspiele in den meisten Fällen verhältnismäßig einfach zu erlernen. Man muss nicht lange trainieren. Dies erleichtert vor allem Einsteigern das Spielen. Gerade in Bibliotheken ist dies von großer Bedeutung. Bewegungsspiele sind darüber hinaus eine gute Möglichkeit, interessierten Personen die Möglichkeiten des Themas Gaming zu zeigen. Bei vielen komplizierteren Spielen, fällt es dem Zuschauer schwer überhaupt zu verstehen, was auf dem Bildschirm passiert. Auch die Nutzung der Controller wird nicht auf den ersten Blick verständlich. Bewegungsspiele sind aber in der Regel einfach zu verstehen. Die Interaktion des Spielers mit dem Spiel wird sofort sichtbar. Wenn also Bibliotheken mit Gaming arbeiten wollen, sollten sie auf jeden Fall auch Bewegungsspiele anbieten bzw. vorstellen.

Bewegungsspiele eignen sich auch für wissenschaftliche Bibliotheken. Vor allem wenn die Bibliothek einen Ort der Ablenkung (nicht der Ruhe) anbieten möchte. In vielen wissenschaftlichen Bibliotheken haben wir Räume des Arbeitens und der Stille. Was sehr oft fehlt ist ein Ort der Ablenkung oder der Zerstreuung. 
Unabhängig davon wird die sogenannte „Gestensteuerung“ an Bedeutung gewinnen. Die BSB in München und die Bibliothek der ETH in Zürich haben bereits eigene Projekte verwirklicht, die auf der Nutzung einer Gestensteuerung basieren. Hier wird die Bibliothek zu einem Innovationsträger bzw. einer Innovationsbühne.

Genre: Tanz- bzw. Bewegungsspiele

Beschreibung: Spiele bei denen sich der Spieler interagierend zum Spiel in der realen Welt bewegt.

Beispiele: Just Dance, Kinect Joyride, Kinect Adventures

Voraussetzungen: PC oder Konsole

\section{Sportspiele}

Das Thema Sportspiele ist ebenfalls relevant für Bibliotheken. Auch hier sind die Grenzen zu anderen Genres fließend. So gibt es Sportspiele, die Simulationen oder Rennspiele sind. Trotzdem hat man dieser Gruppe ein eigenes Genre zugeordnet. Man kann den Bereich Sportspiele in fünf Bereiche einteilen:

1. Sport-Manager-Simulationen: Bei diesen Spielen ist nicht der Sport sondern das Management z. B. eines Sportvereins der zentrale Inhalt. In Deutschland sind z. B. Management-Simulationen wie der Fußballmanager von Electronic Arts erfolgreich. Bei diesen Spielen schlüptt man in die Rolle eines Managers eines Sportvereins. Man ist mit einer Vielzahl an Aufgaben betraut. Dazu gehören u.a. das Training und die Spiele der Mannschaften, die Finanzen des Vereins, das Marketing, der Ausbau der Infrastruktur, das Personalmanagement etc. Diese Spiele sind äußerst komplex. In aktuellen Versionen kann man zudem einen Spieler in den jeweiligen Partien spielen.

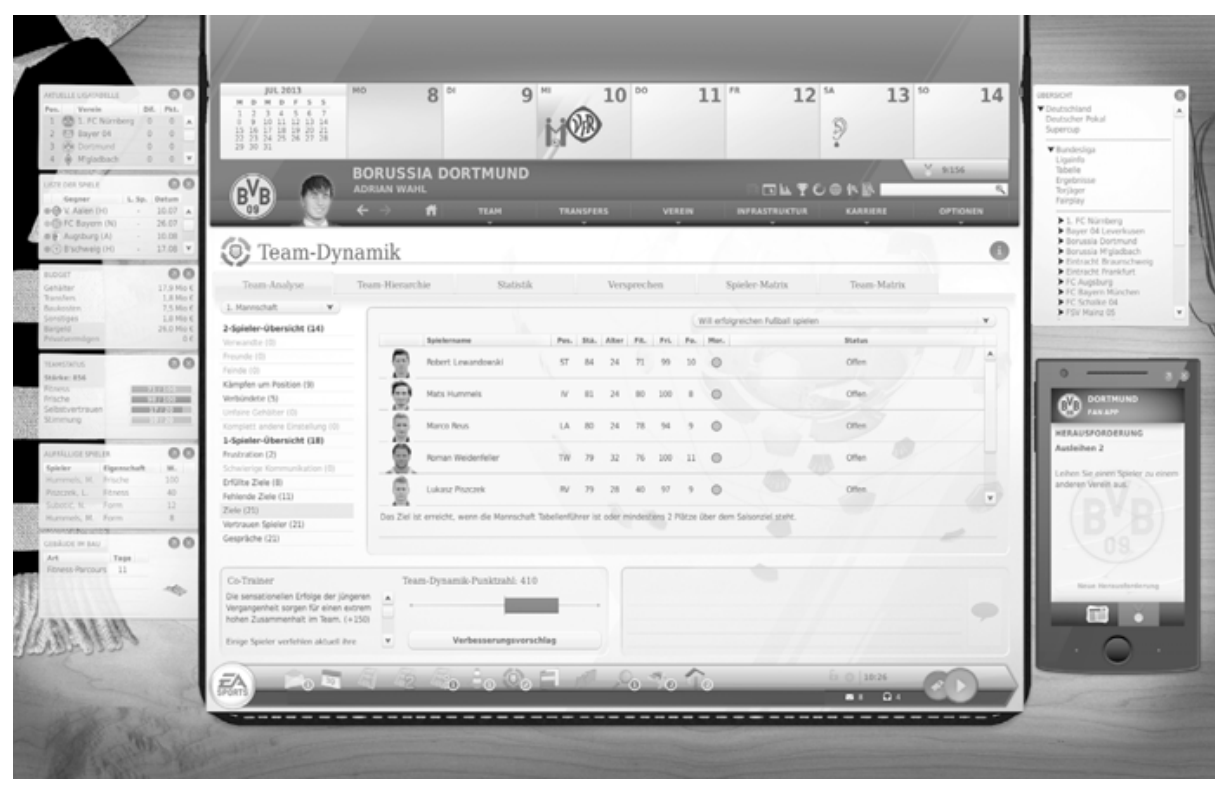

Abb. 13 Screenshot aus dem Spiel Fussball-Manager14 von Electronic Arts. Mit freundlicher Genehmigung von Electronic Arts. 


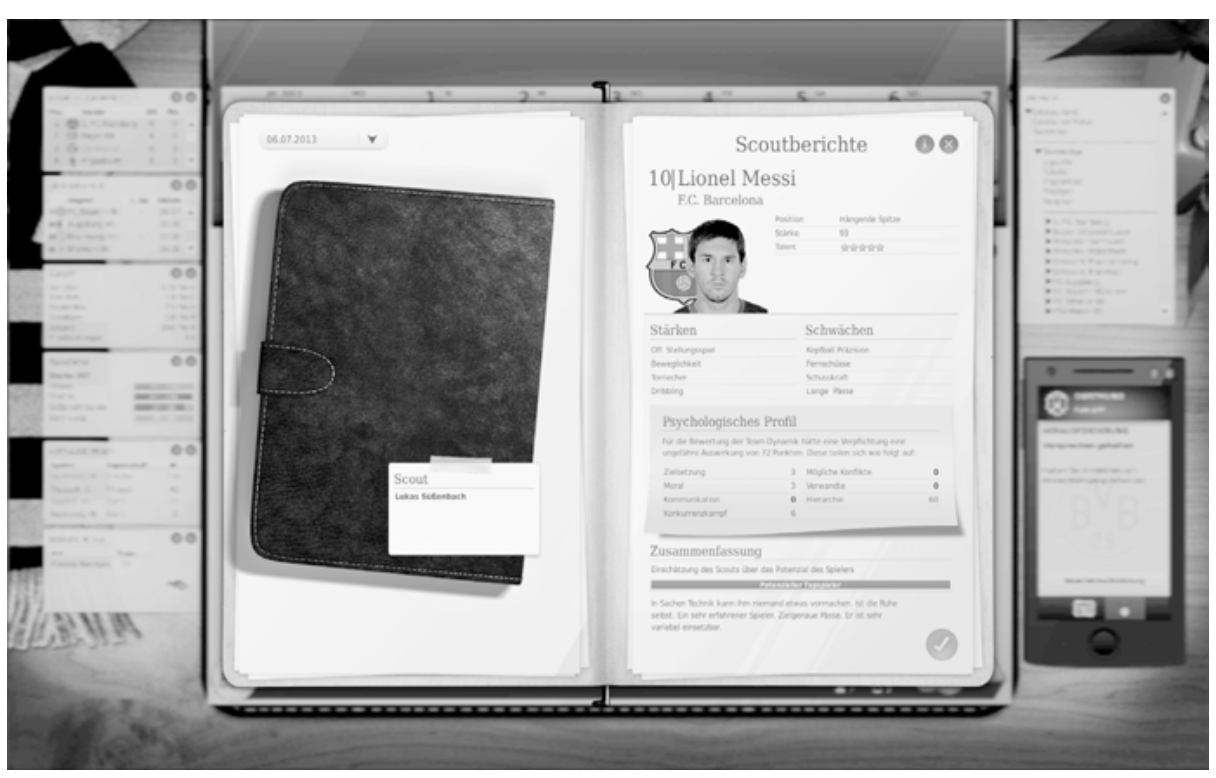

Abb. 14 Screenshot aus dem Spiel Fussball-Manager14 von Electronic Arts. Mit freundlicher Genehmigung von Electronic Arts.

2. Sport-Simulationen: Dieser Begriff ist von mir entwickelt worden und umfasst alle Spiele, bei denen der jeweilige Sport simuliert wird. Dabei kann es sich um ganz unterschiedliche Sportarten handeln. So gibt es Simulationen für Golf, Tennis, Basketball, Fussball etc. In Deutschland sind vor allem Fussball-Simulationen beliebt. Besonders erfolgreich sind die FIFA-Serie von Electronic Arts und PESSerie von Konami. Das Spielen dieser Spiele ist nicht einfach und man benötigt einige Zeit, um die einzelnen Funktionen und Abläufe zu verstehen, aber dann macht es großen Spaß. Die Entwickler dieser Spiele versuchen ein möglichst realitätsnahes Erlebnis zu erzeugen. So werden die Spiele z.B. durch OriginalKommentatoren kommentiert. Zudem wird großer Wert auf die Geräusche der des Stadions gelegt. Dies geschieht u.a. durch das Aufnehmen der Töne und Geräusche in echten Stadien.

3. Sport-Bewegungs-Spiele: Hierzu gehören alle Sport-Spiele, die man auf der XBOX360 mit Kinect, auf der Playstation 3 mit Move und auf der Wii U mit der Wiimote spielt. Auch hier gibt es alle möglichen Variationen und dargestellten Sportarten. Auch die Tanzspiele gehören m.E. Zu dieser Kategorie. Natürlich sind diese Spiele nicht so komplex und schwer zu lernen wie die Sport-Simulationen, die komplexere Controller haben. Dafür ist aber der Einstieg leichter.

4. Rennspiele: Es gibt eine Vielzahl an Rennspielen, vor allem im Bereich der Autorennen. Grundsätzlich ist dies ein eigenes Genre. Sie gehören aber trotzdem auch zu den Sportspielen. Bei den Rennspielen handelt es sich zumeist um Spiele, in denen Autorennen und vergleichbare Wettbewerbe simuliert werden. Der Spieler kann diese Spiele mittels Controller oder mittels eigenem Körper als Controller spielen. Auch hier sind letztere einfacher zu spielen und damit leichter zugänglich, während erstere sehr komplex sind und eine gewisse Zeit des Trainings und der Einarbeitung benötigen.

5. Real-Life-Sport-Games: Diese Gruppe bezeichnet die Spiele, die ein Spielsystem mit Aktivitäten in der realen Welt vernetzen. Hierzu gehören z. B. Jogging-Spiele, bei denen der Spieler in der Realität joggt und seine zurückgelegte Strecke mittels GPS und dem Smartphone aufgezeichnet wird. Dabei tritt der Spieler ge- 
gen andere reale Läufer an. Er kann zudem für bestimmte Strecken und Zeiten Punkte bekommen. Mehr zu diesem Themenkomplex erfahren Sie unter „Gamification“.

Sportspiele eignen sich ebenfalls sehr gut für die Nutzung in Bibliotheken. In den meisten Fällen besteht keine Altersbeschränkung, Sie beschäftigen sich zudem mit Inhalten, die in unserer Gesellschaft bekannt und relevant sind. Fussball ist z. B. eine Volkssportart. Die verschiedenen Variationen lassen wiederum unterschiedliche Angebote zu. Von Wettbewerben, bei denen die Spieler beispielsweise gegeneinander Fußball spielen bis hin zu Aktivitäten in der realen Welt, bei denen die Spiele die realen Aktivitäten begleiten, gibt es eine Vielzahl an Möglichkeiten. Da die Themen eine hohe Akzeptanz in der Bevölkerung haben, kann man auch parallel zu Großereignissen in der realen Welt Veranstaltungen in der Bibliothek mit Games veranstalten. So könnte man z. B. zur Fußball-Weltmeisterschaft ein eigenes Turnier in der Bibliothek veranstalten.

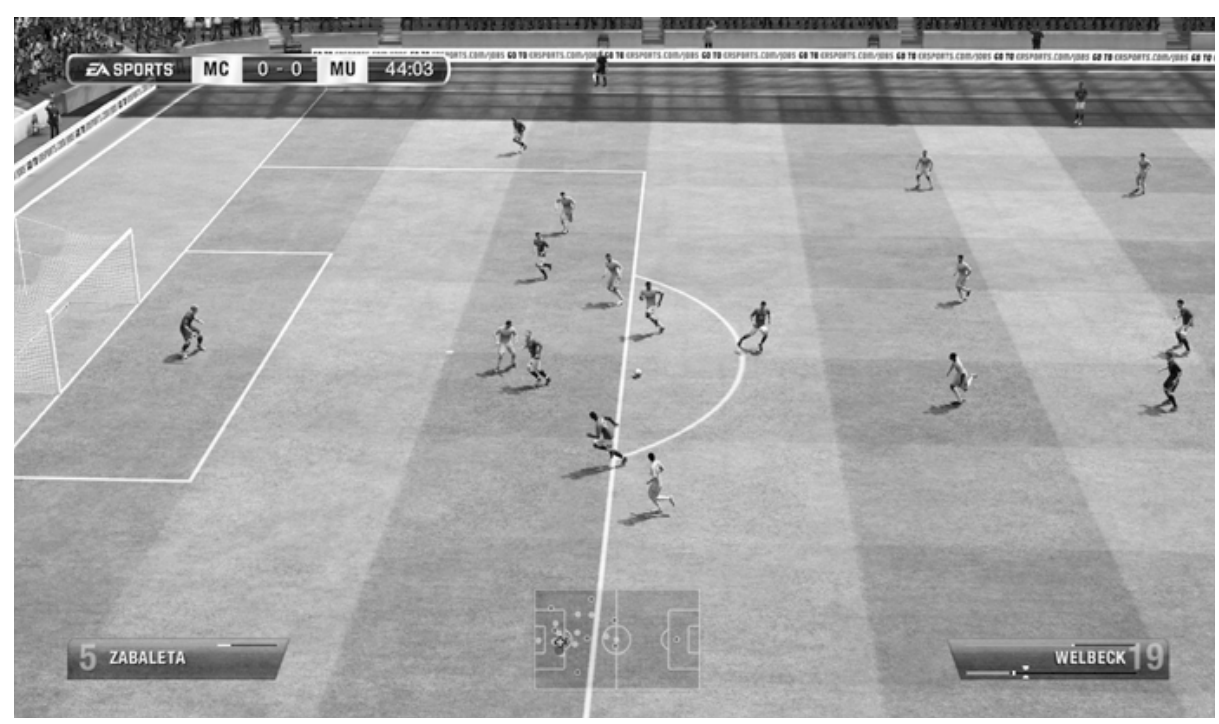

Abb. 15 Screenshot aus Fifa 13 von Electronic Arts. Mit freundlicher Genehmigung von Electronic Arts.

Genre: Sportspiele

Beschreibung: Spiele bei denen es um Sport geht. Dabei kann es sich um Simulationen, Bewegungsspiele etc. gehen

Beispiele: Fussball-Manager von Electronic Arts, Pro Evolution Soccer, FIFA, Formula 1 Voraussetzungen: PC oder Konsole oder Mobile Device

\section{Simulationen}

Der Begriff „Simulationen“ ist ein bisschen irreführend, denn letztlich sind alle Computerspiele Simulationen. Insofern gilt auch hier die Aussage, die ich schon bei anderen Genres getroffen habe: es mag zu Überschneidungen kommen. Heutige Computer und Konsolen lassen die Simulation von komplexen Welten zu. Dabei ist es egal, ob es sich dabei um die Simulation der Realität, z. B. Sport-Manager-Spiele oder um eine Simulation einer virtuellen Realität z. B. in Form von komplexen Zukunftswelten handelt. Die Simulationen haben eine große Schnittmenge mit Strategiespielen, welche
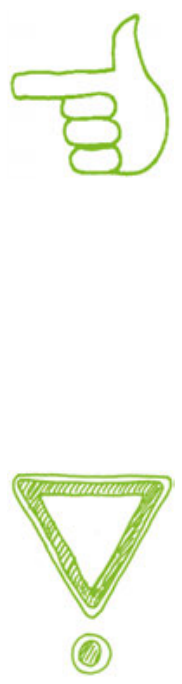
ich auch noch beschreiben werde. Im Folgenden möchte ich nun beispielhaft verschiedene Simulationstypen beschreiben:

1. Wirtschaftssimulationen: Bei diesen Simulationen werden mehr oder weniger komplexe Wirtschaftssysteme simuliert. Man schlüpft in der Regel in die Rolle eines Managers, der ein Unternehmen oder einen Wirtschaftsraum steuern soll. Hierzu gehören Spiele wie die Tycoon-Serie (Railroad-Tycoon, Rollercaster-Tycoon etc.) sowie die Sim-City Reihe. Je größer das Spiel ist, desto komplexer sind die Aufgaben und Daten die man bearbeiten muss. Bei einigen Spielen verbringen die Spieler weniger Zeit mit dem eigentlichen Spiel als mit der Bearbeitung von Excel-Listen und der Recherche in Foren und Datenbanken. Diese Spiele dauern sehr lange und erfordern die Bereitschaft kontinuierlich zu lernen.

2. Eine andere Form von Simulation sind die sogenannten Flugsimulationen. Bei diesen Simulationen wird das Fliegen von Flugzeugen, Hubschraubern etc. simuliert. Auch hier gibt es verschiedene Ansätze. Eine Variante ist die wirkliche Simulation eines echten Cockpits. Vor allem die Microsoft Flugsimulationen sind hier erfolgreich. Dabei wird ein reales Cockpit z. B. eines echten Flugzeugs simuliert. Der Spieler fliegt reale Strecken in der realen Zeit. Das kann bedeuten, dass der Spieler acht Stunden lang die Strecke Frankfurt/Main - New York simuliert fliegt. Die Qualität dieser Simulationen ist beeindruckend. Und in Teilen soll sie auch bei der Ausbildung von Piloten eingesetzt werden. Eine andere Form von Simulationen sind diese, bei denen das Fluggerät nicht zu 100\% simuliert wird. Diese Simulationen sollen eher ein Gefühl des Fliegens vermitteln. In manchen Fällen ist dies auch nur ein Teil eines Spiels. Man könnte Flugsimulationen auch Technologie-Simulationen nennen es gibt vergleichbar zu den Flugsimulatoren auch andere Simulatoren z. B. für Landmaschinen. Auch diese Simulatoren versuchen, möglichst eine Kopie der Realität zu sein. Neben der Detailgenauigkeit ist vor allem das Spielen in „Real-Time“ also in der Geschwindigkeit, wie sie auch in der analogen Realität existiert ein wichtiges Kriterium.

3. Lebenssimulationen: Diese Simulationen sollen „echtes Leben“ simulieren. Das bekannteste Beispiel ist mit Sicherheit das Spiel „Die Sims“. Bei diesem Spiel geht es um das Leben einer virtuellen Familie inkl. Häuser bauen, Freundschaften schließen, Geld verdienen etc. Die Sims sind nebenbei bemerkt eines der am meist verkauften Spiele überhaupt.

4. Weitere Formen: In diese Kategorie fallen alle weiteren Formen von Simulationen, wenn sie vor allem die Realität virtuell simulieren. So gibt es z. B. Simulatoren im Bereich U-Boote oder Autorennen oder aber bezüglich dem erneuten Erleben historischer Ereignisse. Letztlich gesehen stellt sich immer die Frage, wie hoch der Grad einer Simulation ist, bzw. ab wann eine Simulation anfängt. In manchen Spielen wird eine reale Umgebung simuliert, in der aber eine fiktive Geschichte erzählt wird.

Simulationen eignen sich ebenfalls für die Anwendung in Bibliotheken. Allerdings ist dies weniger ein Thema für die Bestandsarbeit als vielmehr ein Inhalte für weitergehende Aktivitäten. Simulationen, die sehr viel Zeit benötigen, werden in der Bibliothek nur selten spielbar sein. Hierfür müsste man dann z. B. Teams bilden, die sich dann kontinuierlich abwechseln. Gerade Flugsimulationen eignen sich aber für Projekte, bei denen z. B. Informations- und Medienkompetenz vermittelt werden soll. So wäre es möglich, den Spielern die Aufgabe zu geben, nach bestimmten Informationen zu ausgesuchten Flugzeugen zu suchen. Bei Wirtschaftssimulationen könnte die Suche nach Sekundärinformationen ebenfalls Teil einer solchen Aufgabenstellung im Rahmen eines Projektes sein. 


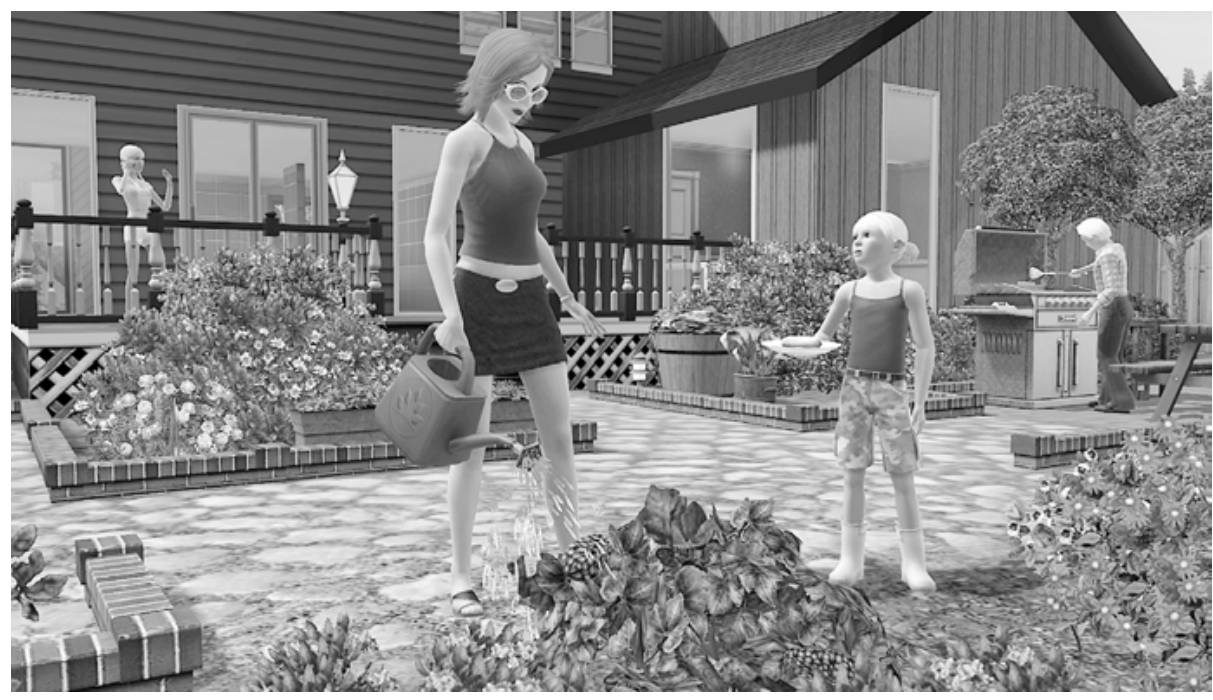

Abb. 16 Screenshot aus dem Spiel Die Sims 3 von Electronic Arts. Mit freundlicher Genehmigung von Electronic Arts.

\section{Genre: Simulationen}

Beschreibung: Spiele bei denen Orte, Technologien, Wirtschafts- und Gesellschaftssysteme simuliert werden.

Beispiele: Sim City, Railroad-Tycoon, Landwirtschaftssimulator

Voraussetzungen: PC oder Konsole oder Mobile Device

\section{Rennspiele}

Willkommen in der Welt der Rennspiele. Diese Spiele erfreuen sich sehr großer Beliebtheit. Es gibt eine Vielzahl an unterschiedlichen Ansätzen. Die heutige Technologie ermöglicht eine realitätsnahe Darstellung realer Rennen wie z.B. aus der Formel 1. Des Weiteren können dadurch auch die komplexen Fragestellungen aus realen Rennen übernommen werden. Dies betrifft z. B. die Reifenwahl oder die Einstellung des Autos. Man tritt dabei entweder gegen den Computer oder aber gegen andere Spieler an. Letztlich kann man dieses Genre in zwei relevante Bereiche aufteilen:

1. Rennspiele, die reale Rennen simulieren: Hierbei sind wir wieder bei der Frage, ob solche Spiele Rennspiele, Simulationen oder beides sind? Bei diesen Spielen geht es darum, reale Rennen zu fahren. Ein gutes Beispiel sind Formel-1-Rennen. Hierbei werden die originalen Schauplätze möglichst detailgetreu dargestellt. Man fährt also auf dem Nürburgring oder dem Hockenheimring. Man ist ebenso verantwortlich für die richtige Einstellung des Wagens. Die heutigen Computer und Konsolen können Formel-1-Rennen so detailgetreu darstellen, dass es dem Zuschauer nur sehr schwer möglich ist, zwischen der Original-TV-Übertragung und dem Spiel zu unterscheiden.

2. Rennspiele die in fiktiven Welten stattfinden. Hierbei handelt es sich um Rennen mit verschiedenen Fahrzeugen in virtuellen Welten. Hierzu gehört sowohl die „Need for Speed“-Reihe als auch „Mario Kart“. Diese Rennspiele verfolgen wiederum unterschiedliche Ansätze. Sie erzählen unterschiedliche Geschichten und richten sich an unterschiedliche Zielgruppen. 


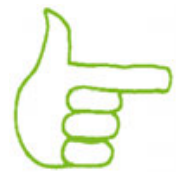

Rennspiele eignen sich sehr gut für Nutzung in Bibliotheken. In den meisten Fällen sind sie sehr leicht zu erlernen und machen den Spielern in der Regel großen Spaß. Hierbei kommen wahrscheinlich vor allem die Spiele, die ich unter Punkt 2 beschrieben habe zur Anwendung. Ein gutes Beispiel ist Mario Kart. Dieses Spiel wurde auch während der Deutsch-Amerikanischen Gaming-Liga für Bibliotheken des Vereins Zukunftswerkstatt Kultur- und Wissensvermittlung e.V. gespielt. Gerade auch für Rennspiele gibt es Versionen mit Bewegungssteuerung.

Für die Rennspiele ohne Bewegungsteuerung gibt es zudem spezielle Controller, die zumeist die Form eines Lenkrades haben. In einigen Fällen gibt es sogar zusätzlich eine Gangschaltung sowie Fußpedale. Die letzte Ausbaustufe sind dann komplette Sitze inkl. Lenkrad und Fußpedalen.

Ein für Bibliotheken besonders interessantes Spiel ist „Trackmania“. Bei diesem Rennspiel werden die Rennstrecken von den Spielern gebaut. Weitere Informationen dazu finden Sie im Abschnitt „Gaming in Bibliotheken“.

Rennspiele eigenen sich hervorragend für die Anwendung in Bibliotheken. Rennspiele sind sehr beliebt und man kann mit Ihnen gut Wettbewerbe veranstalten. Achten Sie unbedingt darauf, dass Sie Spiele nehmen, die man sehr schnell erlernen kann. Spiele wie z. B. die Dirt-Serie sind eher schwer zu spielen. Alternativ können Sie auch vorab Trainingscamps veranstalten.

Genre: Rennspiele

Beschreibung: Spiele in denen verschiedene Rennen simuliert werden. Sie können auch Open-World-Elemente haben.

Beispiele: Dirt, Need for Speed, Formula 1, Mario Kart, Trackmania

Voraussetzungen: PC oder Konsole oder Mobile Device

\section{Rollenspiele}

Kommen wir nun zu einem ganz anderen Genre: den Rollenspielen. Dieses Genre ist nicht erst mit dem Aufkommen der Computerspiele entstanden. Es gab und gibt auch in der analogen Welt sehr erfolgreiche Rollenspiele. Die Rollenspiele aus der Welt der Computerspiele sind also letztlich eine Weiterentwicklung einer viel älteren Kultur.

Das Modell der Rollenspiele ist verhältnismäßig einfach. Der Spieler schlüpft in die Rolle einer fiktiven Figur und erlebt deren Abenteuer bzw. löst Rätsel und Aufgaben. Die Identifikation mit der Figur und der Spielewelt kann sehr stark sein. So gibt es Spieler, die die Gamescom verkleidet als ihre Spielfigur besuchen. Hier gibt es in manchen Fällen eine Verbindung mit dem Bereich „Cos-Play“, bei dem sich die Akteure ebenfalls verkleidet als virtuelle Figur treffen.

Rollenspiele sind in der Regel sehr komplex. Neben dem eigentlichen Spiel entsteht zumeist eine virtuelle Welt aus Foren, Wikis, Webseiten, Clubs etc. die für die Vernetzung der Teilnehmer sowie das Teilen von Informationen genutzt werden. Rollenspiele sind keine Spiele, die man mal eben so nebenbei spielt. Die Charaktere oder auch Avatare müssen zumeist in einem längeren Zeitraum entwickelt werden. Hierzu gehören bestimmte Fähigkeiten, Waffen, Kleidung etc.

Es gibt wie bereits erwähnt eine Vielzahl an Aufgaben und Rätseln für deren Lösung die Spieler Punkte, Fähigkeiten, Stärke etc. bekommen können. Der Spieler kann gegen den Computer oder gegen andere Spieler antreten. Ebenso gib es Spiele, die es erfordern, dass man sich mit anderen Spielern zusammentut um gemeinsam Aufgaben zu lösen oder gegen andere Gruppen anzutreten. 
Genre: Rollenspiel

Beschreibung: Spiele bei den der Spieler in die Rolle einer virtuellen Figur schlüpft und in einer mehr oder weniger komplexen Welt Abenteuer erlebt. Die Spiele können sowohl alleine als auch zusammen mit anderen Spielern gespielt werden.

Beispiele: Diablo, The Secret World, The Elder Scrolls

Voraussetzungen: PC oder Konsole oder Mobile Device

\section{Massively Multiplayer Online Role-Play Games oder auch MMORPG's}

Bei diesen Spielen handelt es sich um eine Untergruppe der Rollenspiele. Das Modell hinter diesen Spielen ergibt sich aus dem Namen. Es sind Spiele bei denen eine sehr große Zahl an Spielern gleichzeitig online zusammen spielen. Über dieses Genre ließe sich sicher ein eigenes Buch schreiben. Es gehört zu den faszinierendsten Bereichen der Gaming-Kultur. Die Spieler kämpfen gegen andere Spieler oder aber computergenerierte Gegner. Man löst Aufgaben - sogenannte Quests - und entwickelt seine Spielfigur ständig weiter. In diesen Spielen geht es primär um die Fähigkeit, gemeinsam in Gruppen Strategien zu entwickeln um Quests zu lösen oder aber andere Gruppen anzugreifen. Natürlich lassen sich die Spiele auch alleine spielen. Jedoch hat man letztlich nur in der Gruppe eine Chance. Dies macht den Reiz der Spiele aus.

Diese Spiele lassen sich nicht verleihen und auch nicht in einem Standart-Setting in der Bibliothek nutzen. Jedoch kann die Bibliothek der Ort sein, an dem sich die jeweiligen Communities treffen. Darüber hinaus kann die Bibliothek Hilfestellugen z. B. bei der Nutzung von Wikis etc. geben. Oder die Bibliothek nutzt das Spiel um die Gamer zu Beratern z. B. für Wikis etc. zu machen.

Genre: Massively Multiplayer Online Role-Play Games oder auch MMORPG's

Beschreibung: Rollenspiele bei denen eine große Anzahl von Spielern online zusammen spielen

Beispiele: World of Warcraft, EVE Online, The Secret World

Voraussetzungen: PC oder Konsole oder Mobile Device

\section{Strategiespiele}

Sie möchten keine Aliens blutig erlegen und auch kein Zauberer sein? Sie haben aber Spaß am Entwickeln und Ausprobieren von komplexen Strategien? Und sie haben etwas Zeit? Dann sind Strategiespiele genau das richtige für Sie. In diesen Spielen müssen Sie bestimmte Aufgaben lösen wie z. B. eine gegnerische Armee schlagen oder deren Hauptquartier einnehmen. Dabei müssen Sie überlegen, welche Einheiten Sie mit welcher Aufgabe in die Schlacht führen etc. Heutige Strategiespiele sind in der Regel sehr komplex und es bedarf einer Vielzahl an Kenntnissen und Erfahrungen um das Spiel erfolgreich zu spielen. In diesen Spielen spielt man entweder gegen den Computer oder aber gegen andere Spiele. Es gibt auch Spiele, bei denen mehrere Spieler gegeneinander antreten. Zum jetzigen Zeitpunkt gibt es zwei Varianten von Strategiespielen: Echtzeitstrategiespiele und rundenbasiertes Strategiespiele:
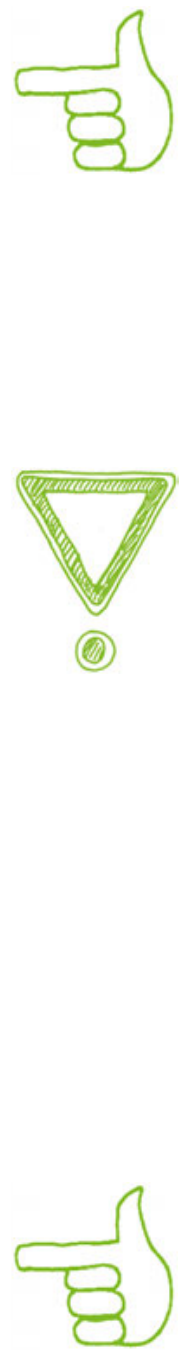


\section{Echtzeitstrategiespiele}

Das besondere bei diesen Spielen ist die Tatsache, dass alle Aktivitäten sowie die Veränderung des Spiels als Ganzes in Echtzeit stattfinden. Somit muss der Spieler kontinuierlich sehr viele Bereiche kontrollieren und daraus resultierende Entscheidungen treffen. Ein Spiel wie „Starcraft“ beinhaltet u. a. folgende Aufgaben:

1. Bauen Sie eine Basis

2. Suchen Sie nach Rohstoffen

3. Bauen Sie Gebäude um z. B. Einheiten zu produzieren

4. Produzieren Sie die Einheiten die Sie Ihrer Meinung nach brauchen

5. Entwickeln Sie eine Angriffsstrategie um das Lager des Gegners anzugreifen

6. Wehren Sie Angriffe des Gegners ab

Alle daraus resultierenden Entscheidungen müssen kontinuierlich an die aktuelle Situation angepasst werden. Das bedeutet, dass Sie als Spieler eine Vielzahl an Parametern kontinuierlich beobachten müssen. Und dieses Beobachten und Entscheidungen treffen, findet mit hoher Geschwindigkeit statt. Das bedeutet, Sie müssen trainieren, trainieren, trainieren.

Es gibt zwei Möglichkeiten ein solches Spiel zu spielen. Entweder Sie spielen es als Einzelspieler gegen den Computer oder aber Sie spielen gegen reale Menschen. Letzteres ist quasi die Königsdisziplin. Ein sehr berühmtes Echtzeit-Strategie-Spiel ist „Starcraft“. In der Variante „Spieler gegen Spieler“ sind in den letzten Jahren globale Ligen entstanden. Diese Wettbewerbe sind äußerst erfolgreich. Tausende Spieler trainieren und spielen gegeneinander. Man nennt dieses Phänomen auch eSports. In Ländern wie Südkorea hat sich eSports zu einem Volkssport entwickelt.

\section{Rundenbasierte Strategiespiele}

Im Gegensatz zu den Strategiespielen, welche in Echtzeit funktionieren, gibt es in rundenbasierten Spielen feste zeitliche Abschnitte. Man kann dieses Modell sehr gut mit Brettspielen wie „Mensch ärgere Dich nicht“ oder „Monopoly“ vergleichen. Dort würfeln Sie und bewegen Ihre Spielfiguren. Danach sind die Mitspieler dran und Sie müssen warten bis Sie wieder dran sind. In rundenbasierten Strategiespielen ist es genauso. Ein gutes Beispiel ist „Civilisation“. Bei diesem Spiel ist es Ihre Aufgabe, eine Zivilisation aufzubauen. Sie beginnen ein paar tausend Jahre vor Christus und haben nur eine beschränkte Zahl an Einheiten zur Verfügung. Im Laufe des Spiels müssen Sie Städte gründen und ausbauen, Einheiten produzieren, Technologien und Wissen entdecken, Kriege führen etc. Zu Beginn einer jeden Runde treffen Sie Ihre Entscheidungen. Daran anschließend bewegen die Mitspieler (Computer oder andere reale Spieler) ihre Figuren bzw. treffen ihre Entscheidungen und danach sind Sie wieder dran. Rundenbasierte Strategiespiele erfordern eine andere Herangehensweise. Es ist notwendig, sehr viele mögliche Schritte der Gegner vorauszudenken.

Durch den sehr oft vorhandenen Wettbewerbscharakter eigen sich diese Spiele sehr gut für Veranstaltungen in der Bibliothek. Dazu gehören eigene Wettbewerbe in der Bibliothek oder auch „Public Viewing“ von großen eSport-Events. Denken Sie daran, dass für Online-Multiplayer-Spiele immer eine gute Internetverbindung brauchen. 
Genre: Strategiespiele

Beschreibung: Spiele bei denen Sie komplexe Strategien entwickeln müssen, um bestimmte Ziele zu erreichen. Man unterscheidet zwischen Echtzeitstrategiespielen und rundenbasierten Strategiespielen.

Beispiele: Civilisation, Starcraft, League of Legends, Ruse

Voraussetzungen: PC oder Konsole oder Mobile Device

\section{Puzzles}

Auch in der digitalen Welt gibt es natürlich Puzzles. Allerdings geht es in diesem Fall nicht um die klassischen Puzzles in einer digitalen Version. Solche Spiele sind auch erhältlich aber nicht wirklich spannend. Aber was wäre, wenn man die Idee der Puzzles mit anderen Elementen heutiger Computerspiele verbinden würde?

Genau diese Idee wurde in verschiedenen Spielen umgesetzt. Ein gutes Beispiel ist das Spiel „Portal“ bzw. „Portal 2“. Dieses Spiel sieht auf den ersten Blick wie ein First-Person-Shooter aus. Wie auch bei den Shootern erlebt man das Spiel mit den Augen der Spielfigur. Zudem hält man eine Waffe in der Hand, die wie ein Gewehr aussieht. Und natürlich kann man damit auch schießen. Und trotzdem ist dieses Spiel kein Shooter. Man tötet niemanden mit der Waffe aber sie ist trotzdem elementarer Bestandteil des Spiels. Man braucht die Waffe um Löcher in die Wände zu schießen. Aus der Waffe werden zwei Formen von Projektilen abgefeuert. Beide Projektile sorgen für Löcher in den Wänden. Diese Löcher sind Portale. Das eine Projektil öffnet einen Eingang zu einem Portal. Das andere Projektil öffnet den dazugehörigen Ausgang. So bewegen Sie sich von einem Punkt des Raumes zu einem anderen, in dem man zuerst mit einem Schuss einen Portal-Eingang öffnet. Mit dem nächsten Schuss öffnet man nun an der Stelle, zu der man gelangen möchte, den Portal-Ausgang. Wenn man nun durch das Portal durchgeht, landet man sofort an dem Punkt des Raumes bei dem das Portal ankommt. Auf diese Art und Weise können verschiedene Hindernisse überwunden werden. Was hier in der Beschreibung einfach klingt ist in der Realität kompliziert und eine große Herausforderung. In Portal 2 können die Spieler auch zusammen mit anderen Spielern spielen, oder aber eigene Räume/ Rätsel erstellen.

Ein anderes spannendes Spiel aus dem Bereich Puzzles ist „World of Goo“. Der Sinn des Spiels ist es, in jedem Level mit den sogenannten Goos eine Brücke zu einem „Absaugrohr“ zu bauen. Wenn diese Brücke gebaut worden ist, können die Goos eingesaugt werden. Ziel des Spiels und der einzelnen Level ist es, so viele Goos durch das jeweilige Rohr zu saugen wie irgend möglich.

Das dritte Beispiel heißt „Contre Jour“ und ist vor allem auf mobilen Endgeräten wie Smartphones und Tablet-PCs ein großer Erfolg. Man kann es aber auch im Browser online spielen. Das Spiel ist verhältnismäßig einfach. Da gibt es dieses kleine sehr niedliche Wesen mit dem Namen „Petit“. Es braucht Ihre Hilfe um ins Licht zu kommen bzw. viele kleine Lichtteilchen zu sammeln. Um das kleine Wesen zu unterstützen müssen Sie die Spielumgebung verändern. Sie erschaffen kleine Rampen, damit „Petit“ dort herunterrollen kann. Oder Sie schaffen kleine Hindernisse, damit die Bewegung von „Petit“ gestoppt bzw. verlangsamt wird. Darüber hinaus können Sie Lianen und andere Gegenstände nutzen, um „Petit“ von einem Ort zum nächsten zu bringen.

„World of Goo“ und „Contre Jour“ sind weitere beeindruckende Beispiele für die Kreativität und den Facettenreichtum der Computergames. Beide Spiele sind sicherlich auch in die Gruppe der sogenannten „Kunstspiele“ einzuordnen, die ich später beschreibe. Spiele wie diese sind kleine Gesamtkunstwerke. Es ist nicht nur das Spie- 
len sondern ebenso die Grafik und die dazu passende Musik, die einen sehr schnell vergessen lassen, dass man ein Computerspiel spielt.

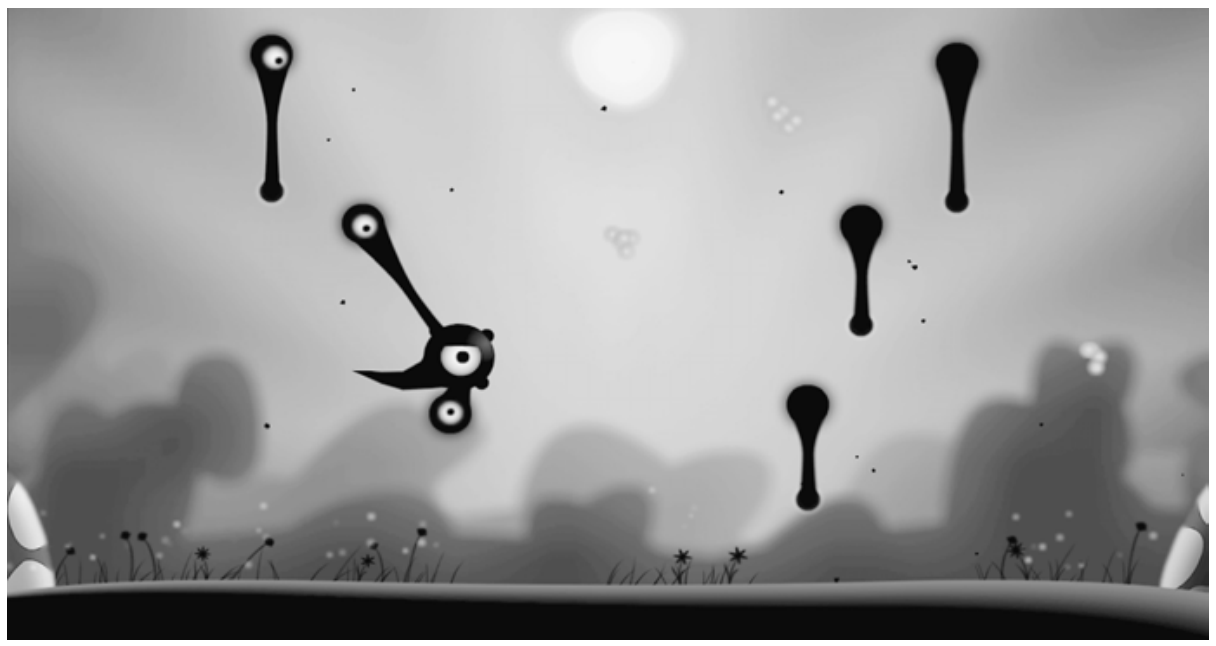

Abb. 17 Screenshot des Spiels Contre Jour

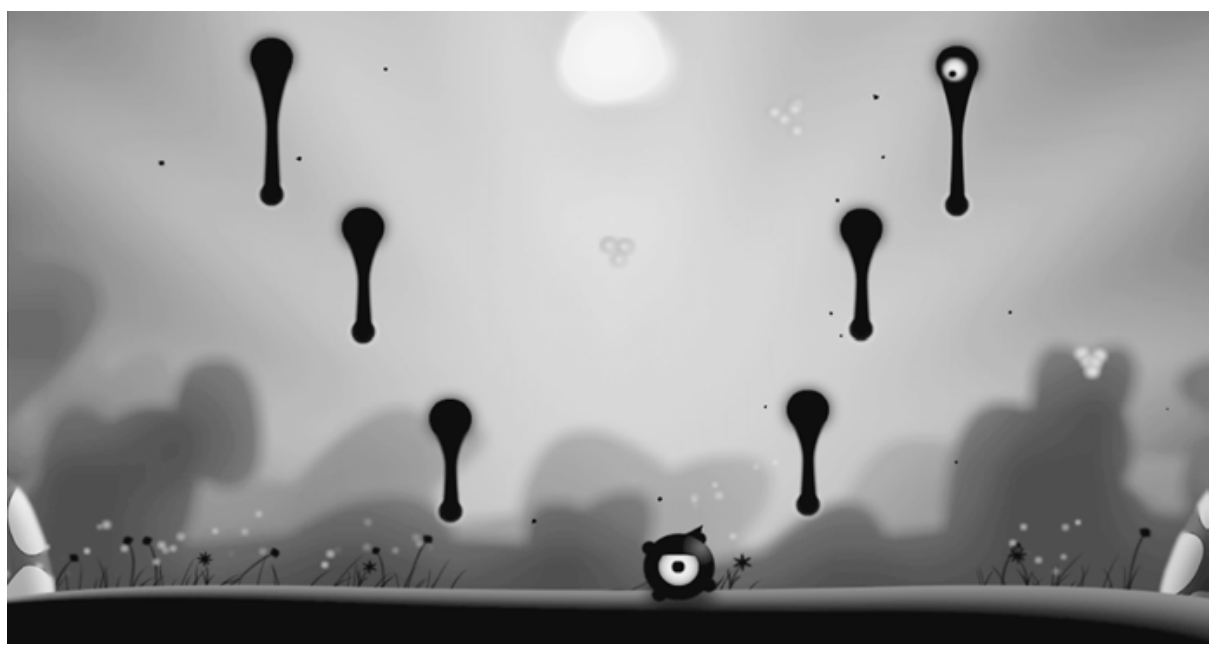

Abb. 18 Screenshot des Spiels Contre Jour

So gerne ich First-Person-Shooter, Strategiespiele und Simulationen spiele, diese Kunstwerke sind für mich die wahren Meisterwerke der Spielkultur.

Durch die zumeist digitalen Vertriebsmodelle wird es schwer, die genannten und viele weitere Spiele in den Bestand aufzunehmen. Aber man kann diese Spiele z. B. für den „Tag des Puzzles“ oder den „Tag des Kunstspiels“ nutzen. Und natürlich hilft ein solches Spiel ungemein wenn es darum geht, Menschen zu zeigen, dass Gaming nicht nur aus Shootern besteht.

\section{Genre: Puzzlespiele}

Beschreibung: zwei- und dreidimensionale Puzzles, die teilweise Elemente aus anderen Genres übernehmen. Einige der Spieler erlauben auch einen Coop-Modus bzw. das selbstständige Entwickeln eigener Puzzles.

Beispiele: Portal 1+2; World of Goo, Contre Jour Voraussetzungen: PC oder Konsole oder Mobile Device 


\section{Musikspiele}

Kommen wir nun zu den sogenannten Musikspielen. Auch hier gibt es wieder eine Vielzahl unterschiedlicher Ansätze und auch hier ist manchmal nicht ganz klar, ob es sich wirklich um ein Musikspiel handelt. Grundsätzlich ist es so, dass nahezu alle Spiele etwas mit Musik zu tun haben. In guten Spielen hat die Musik immer eine wichtige Rolle. Sie unterstützt wie in Filmen auch Spannungsmomente bzw. die Dramaturgie. In manchen Spielen haben die Spielfiguren eigene Melodien vergleichbar mit der berühmten „Darth Vader“- Melodie in Star Wars.

Manche Soundtracks zu Spielen haben sogar Preise gewonnen. Die Gamesconvention in Leipzig - der Vorgänger der Gamescom - wurde mit einem Konzert eröffnet, bei dem die besten Werke aus Spielen des vergangenen Jahres uraufgeführt wurden. Spiele wie „Contre Jour“ wären ohne die Musik und die verschiedenen Geräuscheffekte nur halb so interessant. Musik und Geräusche sind also ein elementarer Bestandteil von Computerspielen . In diesem Fall geht es aber um Spiele, die sich primär mit Musik befassen. Und wie bei fast allen Genres auch gibt es auch hier wieder verschiedene Ansätze.

In vielen Spielhallen finden sich moderne Musikspiele, bei denen man vergleichbar mit den schon beschriebenen Tanzspielen, Musik hört und bei jedem Ton mit der Hand oder dem Fuß auf eine bestimmte Taste drücken muss. Das Ziel ist dabei, im richtigen Moment auf die richtige Taste bzw. Tastenkombination zu drücken. Das mag einfach klingen - die Musikstücke werden aber immer schneller. Und natürlich gibt es dazu auch richtige Wettbewerbe.

Ein ähnliches Modell verfolgen Spiele wie „Guitar Hero“. Hierbei hat man einen Controller in Form einer Gitarre in der Hand. Man hört nun einen Song und muss die Gitarre dazu spielen. Hierfür greift man am Hals der „Gitarre“ den richtigen Ton und schlägt im Takt die virtuellen Saiten. Auf dem Monitor sieht man dann eine Art Musikvideo sowie den Hals der Gitarre, auf dem die anzuschlagenen Tasten gezeigt werden. Sieger ist der Spieler, der am meisten Töne in der richtigen Tonhöhe und zum richtigen Zeitpunkt gespielt hat.

Als drittes Beispiel dienen hier die verschiedenen Gesangsspiele. Am bekanntesten ist dabei sicherlich „Singstar“. Dieses Spiel ist vergleichbar mit Karaoke - nur eben für die Playstation. Man singt durch spezielle Mikrofone verschiedene Songs zu einem Playback. Der Spieler sieht ein Video und bekommt zudem angezeigt, wann er welchen Ton singen muss. In diesem Spiel gewinnt man, wenn man möglichst viele Töne in der richtigen Tonhöhe zum richtigen Zeitpunkt getroffen hat.

Musikspiele eignen sich hervorragend für Aktivitäten in der Bibliothek. Achten Sie nur darauf, dass Sie daraus einen besonderen Event machen. Suchen Sie nach etwas, was man nur in der Bibliothek aber nicht zuhause bekommen kann. So können Sie z. B. eine richtige Bühne aufbauen oder für ein großes Publikum sorgen.

Genre: Musikspiele

Beschreibung: Spiele bei denen sich alles um Musik dreht. Dies können z. B. Spiele sein, bei denen man interaktiv auf Musik reagiert. Eine weitere Möglichkeit ist das

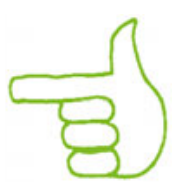
„Spielen“ von Instrumenten oder auch Karaoke-ähnliche Spiele.

Beispiele: Guitar Hero, Bit.Trip.Beat; Singstar, Audiosurf

Voraussetzungen: PC oder Konsole oder Mobile Device 


\section{Quiz-Spiele}
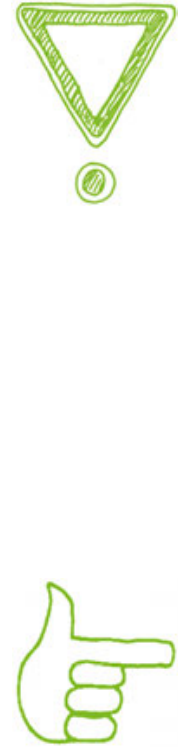

Genre: Quizspiele

Beschreibung: Spiele bei denen ich alleine oder mit anderen zusammen Fragen aus verschiedenen Bereichen beantworten muss.

Beispiele: Buzz, Trivial Pursuit, Wer wird Millionär?

Voraussetzungen: PC oder Konsole oder Mobile Device

\section{Kunstspiele}

Ich weiß ehrlich gesagt nicht, ob es dieses Genre wirklich gibt, oder ob ich durch die Nennung des Genres zu seinem Erfinder werde. In den letzten Jahren sind aber immer mehr Spiele auf den Markt gekommen, die zum einen nicht richtig in eines der genannten Genres passen und zum Anderen eher an kleine Kunstwerke denn an Spiele erinnern. In diesen Spielen spiegelt sich m. E. eine neue Kunstform wieder, die zudem für Bibliotheken sehr interessant sind. Am Beispiel eines ausgesuchten Spiels möchte ich kurz beschreiben, was ich mit dem Begriff „Kunstspiele“ meine und warum diese Spiele für Bibliotheken so interessant sein könnten.

Auf der letzten Gamescom war ich wie immer auf der Suche nach Spielen, die das Spektrum des Gamings erweitern. Natürlich werden auf der Gamescom Massen an neuen Spielen gezeigt. Und doch muss man nur ein bisschen suchen und man wird reich belohnt. Am Messestand von Sony entdeckte ich „Unfinished Swan“. Dieses Spiel hat mich zutiefst beeindruckt. Das Spiel an sich ist sehr einfach: der Spieler sucht in einer dreidimensionalen Welt nach einem weißen Schwan. Das Problem ist dabei, das die gesamte Welt komplett weiß ist. Man sieht auch keine Konturen oder ähnliches. Der Bildschirm ist komplett weiß. Somit kann man auch nicht sehen ob und wenn ja wohin man sich bewegt. Um dies zu ändern wirft man schwarze Farbkugeln, die, wenn Sie irgendwo auftreffen, zerplatzen und dann einen Teil des Raumes zeigen. Die Darstellung ist wie in einem First-Person-Shooter, d.h. man sieht die Welt durch die Augen der Hauptfigur.

Durch das Werfen der Farbkugeln entsteht eine Art Gemälde. Jeder Durchlauf des Spieles lässt ein neues Kunstwerk entstehen. Das Ganze wird untermalt von einer verspielten Melodie und es macht sehr großen Spaß.

Mit Sicherheit sind diese Spiele nicht der große Mainstream. Jedoch können vor allem Bibliotheken mit diesen Spielen sehr viel anfangen. Meine Empfehlung wäre, eine Playstation 3 inklusive Move-Controller in der Bibliothek fest zu installieren. Die- 
ses Spiel ist für alle Altersklassen freigegeben. Die Bibliothek kann damit zeigen, was Computerspiele auch sein können. Und sie kann damit neue Zielgruppen zum Ausprobieren der Technologie und eines Spiels animieren.

Kunstspiele haben zudem den Vorteil, dass sie zeitlos sind. Abseits des sich schnell verändernden Gaming-Mainstreams sind solche Spiele etwas Besonderes. Hier kann die Bibliothek mit dem Wissen über besondere Spiele abseits der VerkaufsCharts punkten.

Genre: Kunstspiele

Beschreibung: Spiele unterschiedlicher Art, die weniger wie Spiele und mehr wie interaktive Kunstwerke wirken.

Beispiele: Unfinished Swan, Journey, Contre Jour

Voraussetzungen: PC oder Konsole oder Mobile Device

\section{Adventures}

Adventures sind wie der Name schon sagt Abenteuer-Spiele. Die Abgrenzung zu anderen Genres ist hier besonders schwer, da letztlich die meisten Spiele in irgendeiner Form etwas mit einem Abenteuer zu tun haben. In Adventures besteht das Abenteuer z. B. aus einer mehr oder weniger komplexen Geschichte, verschiedenen Aufgaben für die Spieler, Rätseln etc. Auch die Vermittlung der Inhalte kann sehr unterschiedlich sein. So muss man in manchen Spielen bestimmte Personen/Figuren finden und mit ihnen kommunizieren um neue Erkenntnisse zu gewinnen. Selbst die Visualisierung ist unterschiedlich. Gerade zu Anfang dieses Genres handelte es sich zumeist um rein text-basierte Spiele während wird es heute mit zumeist komplexen 2D- oder 3D-Welten zu tun haben.

Allerdings sind die Textadventures nicht vollständig verschwunden. Vor allem in der Vernetzung bzw. Nutzung der Social Media-Welt sind sie ein spannendes Genre. Rein textbasierte Adventures haben zudem den Vorteil, dass man sie mit geringerem Aufwand entwickeln kann. Dies bezieht sich nur auf die Grafik. Im Gegenzug müssen dann das Gameplay und die Geschichte sehr gut sein, damit der Spieler nicht nach kurzer Zeit aufhört.

Eine auch durch Bibliotheken umsetzbare Variante sind Echtzeit-Adventures. Hier wird das Spiel in den verschiedenen sozialen Medien gespielt. In diesem Fall ähneln sie sehr manchen Transmedia-Storytelling-Konzepten. Dabei handelt es sich vereinfacht ausgedrückt um eine Geschichte, die über die sozialen Medien erzählt wird. Dabei wird die Geschichte aber nicht parallel auf allen möglichen Kanälen entwickelt. Man beginnt die Geschichte z. B. auf einem Blog, erzählt dann einen Teil auf Facebook, den nächsten auf Twitter um schließlich wieder bei Facebook oder dem Blog zu landen etc. Hier würde das Spiel letztlich auf die verschiedenen Plattformen transferiert werden. Das besondere wäre hier, dass es ein Echtzeitspiel wäre, d.h. es entstünde quasi durch Kommunikation im Netz.

Ein interessantes Spiel aus dem Bereich der textbasierten Adventures ist „Hack Run“. Es ist für iOS und für Android verfügbar. In diesem Spiel, schlüpfen Sie in die Rolle eines Hackers, der einer fiktiven Person bei der Suche nach bestimmten Informationen helfen muss. Das Spiel findet auf der sogenannten Kommandozeilenebene statt, das bedeutet, es sieht aus wie eine alte DOS-Oberfläche. Sie müssen selber die notwendigen Befehle, Passwörter und Dateinamen erstellen. Allerdings hilft Ihnen das Spiel bei Problemen. Das Spiel findet aber nicht nur auf der Textebene statt. An bestimmten Stellen müssen Sie ins Internet gehen um dort Informationen und/oder 
Dateien zu finden. Zudem besuchen Sie dabei fiktive Webseiten, die von den Machern des Spiels extra programmiert und ins Netz gestellt wurden. Diese Spielidee würde sich nebenbei wunderbar für die Vermittlung von Recherche- und Informationskompetenz eignen.

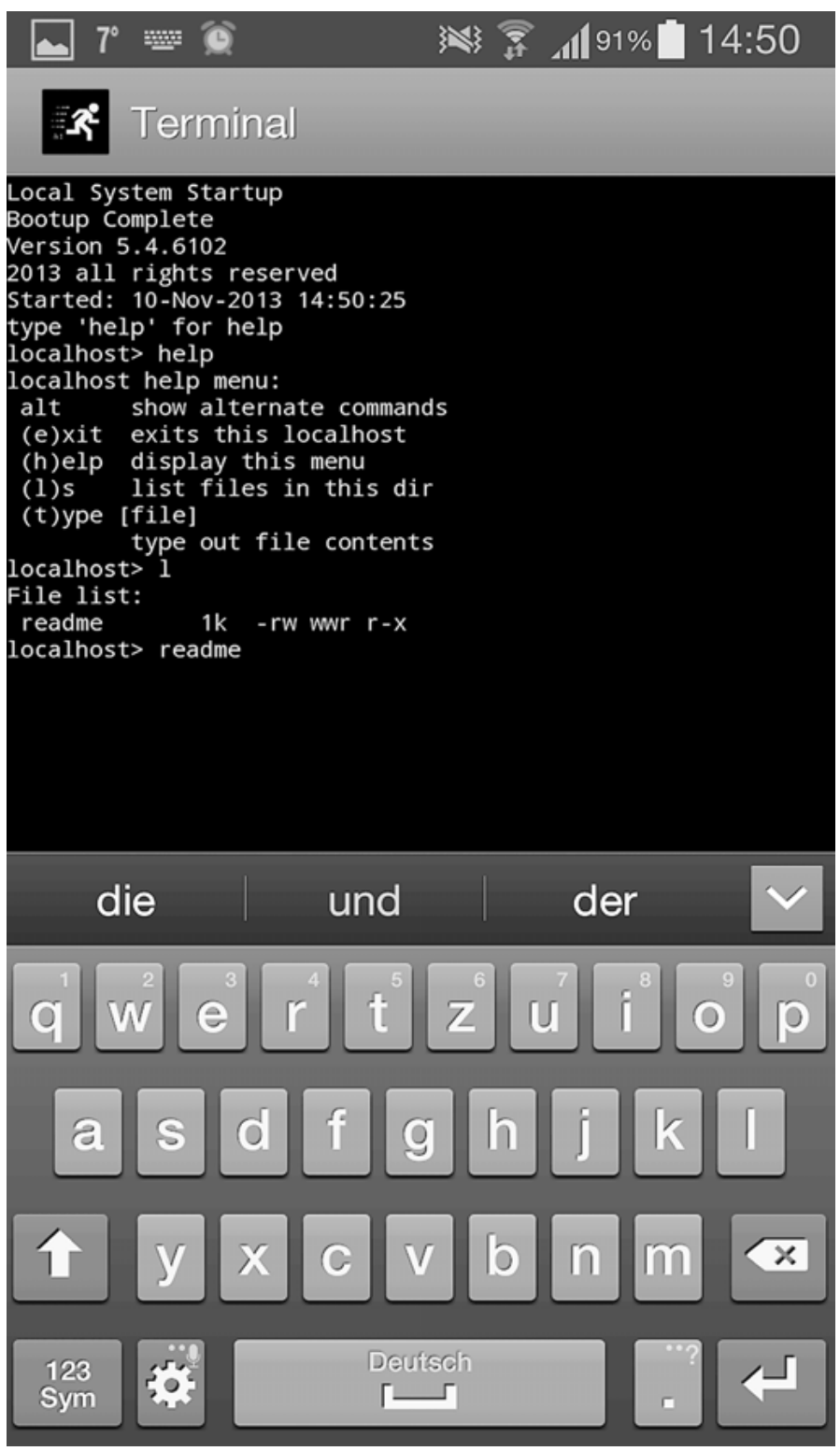

Abb. 19 Screenshot aus dem Spiel Hack Run

Trotzdem haben wir es heute vor allem mit Grafik-Adventures zu tun. Diese stellen, wie der Name schon sagt das Abenteuer grafisch dar. Auch hier haben wir es mit einer stetigen Weiterentwicklung der grafischen Möglichkeiten zu tun. Dabei wird versucht, die jeweilige Welt möglichst detailliert darzustellen. Diese Darstellung betrifft nebenbei auch den Bereich Audio. Gerade wenn es darum geht, eine bestimmte Atmosphäre zu erzeugen, ist das Verhältnis zwischen Audio und Bild sehr wichtig. Die eigentliche Darstellung kann auf verschiedene Art und Weise geschehen. Es gibt Adventure-Games in der First-Person- oder der Third-Person-Perspektive, als Pointand-Click-Adventures und sogar als Jump-and-Run-Game. 
Wenn Sie mit Adventures arbeiten wollen, dann könnten Sie z. B. die Bibliothek im Design des Abenteuers gestalten. Da in Adventures das Abenteuer bzw. die Geschichte im Vordergrund steht, kann man dieses Spiele wunderbar mit anderen Medien wie z. B. Büchern verbinden.

Genre: Adventure

Beschreibung: Spiele bei denen der Spieler im Rahmen einer vorgegebenen Handlung ein Abenteuer erlebt. Dabei steht die jeweilige Geschichte im Vordergrund des Spiels Beispiele: Machinarium, Fahrenheit, Hack Run

Voraussetzungen: PC oder Konsole oder Mobile Device

Im nächsten Schritt kommen wir nun zu weiteren Spielformen. In Teilen geht es dabei um technische Möglichkeiten. Zudem beschreibe ich auch einzelne Spiele:

\section{Online-Gaming}

Kommen wir nun zum Online-Gaming. Online-Gaming ist eigentlich kein Genre sondern vielmehr ein eine bestimmte Art zu spielen. Es ist also unerheblich ob es sich dabei ein Adventure, einen Shooter oder ein Strategiespiel handelt. Online-Gaming bedeutet, dass das eigentliche Spiel nicht auf meinem Computer stattfindet, sondern Online auf einem externen Server. Es gibt hierbei zwei Varianten.

1. Das Spiel wird im Internetbrowser gespielt. Das bedeutet, der Spieler öffnet seinen Browser (z. B. Firefox, Chrome, Internet Explorer, Opera etc.) und der Browser ist der Zugang zum Spiel. Er fungiert also als Schnittstelle. Das Spiel „äuft“ auf einem externen Server. Der Vorteil dieser Variante ist der, dass der Computer keine besonderen technischen Voraussetzungen erfüllen muss. Die Berechnung des Spiels inkl. der Grafik findet extern statt. Der eigene Computer ist quasi die Kontrollstation bzw. das Interface. In manchen Fällen müssen hierfür aber Java oder Flash aktiviert worden sein.

2. Um das Spiel zu spielen, wird ein sogenannter Client heruntergeladen und installiert. Dieser Client ist dann das Interface zum Spiel. Hier sind die technischen Voraussetzungen zumeist höher.

Die Vorteile am Online-Gaming sind vielfältig. So kann man bei der browserbasierten Variante bereits mit einem handelsüblichen Computer spielen, wobei auch keine gesonderte Software notwendig ist. Zudem können über diese Technologie sehr viele Spieler miteinander vernetzt spielen. Immer mehr Spiele haben ein mehr oder weniger sinnvolles Multi-Player-Angebot. Diese Angebote basieren in der Regel auf Clients. Allerdings wird dann auch ein kontinuierlicher Onlinezugang benötigt, was immer noch viele Bibliotheken vor große Herausforderungen stellt. Des Weiteren müssen bei browserbasierten Spielen sehr oft Java und Flash aktiviert sein, was ebenfalls nicht in allen Bibliotheken vorhanden ist. Für die Bestandsarbeit eignen sich diese Spiele nicht, da es keinen physischen Datenträger gibt. Jedoch kann man diese Spiele sowohl im Bereich der Veranstaltungen als auch beim Konzept der „Bibliothek als Spielort“ nutzen. Des Weiteren ist auch hier ein Auskunftsdienst etc. möglich und sinnvoll.

Auch im Bereich Retro-Gaming ist dieses Herangehensweise interessant. Es gibt Plattformen, auf denen man alte Spiele wie z.B. „Pac Man“ oder „Asteroids“ spielen kann. Das Spiel läuft komplett auf einem externen Server und dieser schickt einen Videostream zu Ihrem PC.
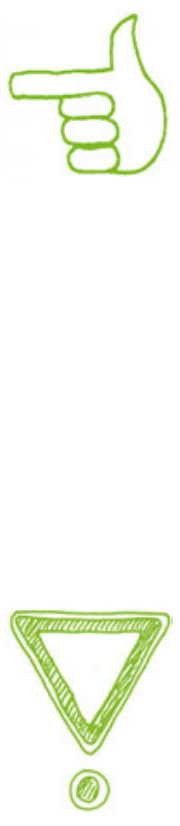

(1) 


\section{Multiplayer}

Auch wenn ich in einigen Darstellungen den Bereich Multiplayer schon beschrieben habe, möchte ich hier nochmal explizit auf dieses Thema eingehen. Mit dem Begriff „Multiplayer-“ oder typisch Deutsch „Mehrspielermodus “ ist das gemeinsame Spielen von mehreren Spielern gemeint. Dabei handelt es sich im zwei oder mehr Spieler, die gemeinsam ein Spiel spielen. Auch hier gibt es wieder verschiedene Varianten:

1. Die Spieler spielen zur selben Zeit, dasselbe Spiel an einer Konsole oder einem PC und teilen Sich dabei den Monitor. Die Einteilung des Monitors nennt man auch „Splitscreen“.

2. Die Spieler spielen an einer Konsole aber nur zwei Spieler sind jeweils aktiv. Dieses Modell ermöglicht, dass größere Teams gegeneinander antreten können. Auch hier wird sehr oft der „Splitscreen“ angewendet.

3. Die Spieler spielen alle an eigenen Systemen, wobei die einzelnen Systeme miteinander vernetzt sind. Ein Beispiel sind die sogenannten „LAN-Partys“ bei denen sich Spieler mit ihren Computern etc. treffen, um zusammen an einem Ort zumeist gegeneinander zu spielen. Es gibt für eine Vielzahl an Genres für solche LAN-Partys. Vor allem Shooter und Echtzeitstrategie-Spiele werden so gespielt. LAN-Partys sind sehr soziale Veranstaltungen. Hier steht vor allem das Spielen in einer Gruppe im Vordergrund. Bibliotheken sollten im Bereich Gaming auf jeden Fall in Betracht ziehen, der Veranstaltungsort für LAN-Partys zu sein. Neben den LAN-Partys findet die Vernetzung der Spieler online statt. Dabei gibt es im Wesentlichen zwei Varianten, die ich beide im vorherigen Abschnitt zum Thema „Onlinegaming“ beschrieben habe.

Wichtig ist in allen Variationen die Mischung aus Wettbewerb und dem gemeinsamen Spielen. Sowohl bei den LAN-Partys als auch bei Mehrspieler-Online-Gaming findet neben dem eigentlichen Spielen sehr viel Kommunikation zwischen den Spielern statt. In manchen Fällen kommunizieren die Spieler miteinander während des Spielens z. B. über Headsets und/oder in einem Chat. Zudem findet bei vielen Spielen vor und nach dem jeweiligen Spiel weitere Kommunikation statt. Ein wesentlicher Inhalt dieser Kommunikation ist der Austausch über das vergangene Spiel um von den Fehlern und Erfolgen zu lernen. Zudem werden in der Diskussion neue Strategien besprochen und geplant. Es gibt aber auch einen Austausch zu Themen, die nichts mit dem gerade gespielten Spiel zu tun haben. Dies können andere Themen aus der Gaming-Kultur wie z. B. neue Technologien, neue Spiele aber auch darüberhinausgehende Fragestellungen sein. Es wird aber auch über alltägliches gesprochen.

Manche Spieler möchten nicht nur ab und zu sondern kontinuierlich miteinander spielen. In solchen Fällen entstehen spezielle Gruppen, die man Clans oder auch Gilden nennt. Die Bezeichnung hängt dabei vom jeweiligen Spiel ab. Diese Gruppen trainieren und spielen gemeinsam. Sie versuchen sich stetig weiter zu entwickeln. Manche Spiele lassen sich nicht alleine erfolgreich spielen, in anderen Spielen ist das gemeinsame Spielen eine Option. Wer Mitglied in einem Clan oder einer Gilde ist, verpflichtet sich, aktiv und kontinuierlich mit zu trainieren und mit zu spielen. In Spielen wie „World of Warcraft“ bedeutet dies u.a. dass man sich zu festen Zeiten online trifft, um z. B. gegen andere Gilden anzutreten.

Wenn Bibliotheken auch im Bereich Multiplayer-Gaming aktiv sein möchten, sei es als Spielort für LAN-Partys oder aber als Standort für Online-Multiplayer-Events, dann benötigen Sie sowohl die dafür notwendigen technischen Ressourcen als auch 
die notwendigen Räumlichkeiten sowie die Offenheit, sich mit diesen Gruppen zu befassen. In diesem Fall geht es nicht mehr darum, ein paar Spiele im Bestand zu haben oder aber hier und da einen kleinen Gaming-Event durchzuführen. Derartige Aktivitäten - die nichts mit der Größe einer Bibliothek zu tun haben - machen nur dann Sinn, wenn sie Teil einer langfristigen Gaming-Strategie sind.

\section{Minecraft}

Es gibt eine Vielzahl an Spielen, die nicht wirklich in eines der herkömmlichen Genres passen. Es gibt auch eine Vielzahl an Spielen die man bis ins Detail beschreiben und auf jeden Fall in Bibliotheken nutzen sollte. Ich habe mir lange überlegt, ob ich mich nicht einfach auf fünf bis sechs Spiele konzentrieren sollte. Aber wenn dies ein Praxisbuch sein soll, dass Ihnen die Welt des Gamings als Ganzes näher bringt, dann macht eine detaillierte Beschreibung von nur ein paar Spielen wenig Sinn. Trotzdem möchte ich beispielhaft für viele andere Spiele ein Spiel hier und in einem der folgenden Kapitel etwas genauer beschreiben: Minecraft.

Ich weiß, dass nur schwer möglich ist Minecraft über eine Beschreibung kennen zu lernen. Sie müssen das Spiel spielen. Unbedingt! Tun Sie es! Am besten jetzt! Natürlich ist es nicht das einzige relevante Spiel aber es zeigt sehr gut, was Gaming sein kann. Minecraft ist wie eine riesige, virtuelle Lego- bzw. Bauklötzchenwelt. Der Spieler findet eine 3D-Welt vor, die komplett aus verschiedenen gleichgroßen würfelförmigen Blöcken besteht. In dieser Welt kann er nun beginnen diese Würfel zu verändern bzw. mit Ihnen etwa zu bauen. Die gesamte Welt besteht aus verschiedenen Rohstoffen, die man abbauen kann. Im Anschluss daran kann man aus diesen Rohstoffen neue Stoffe erstellen und damit dann z. B. Gebäude bauen. Letztlich geht es darum, die vorhandene Welt nach eigenen Wünschen zu verändern bzw. zu gestalten. Das besondere an Minecraft ist, dass es sich um eine offene Welt handelt, das bedeutet der Spieler kann selber entscheiden, was er im Spiel machen möchte. Es gibt keine klaren Vorgaben bzw. Spiele. Aus diesem Grund wird auch immer wieder diskutiert, ob Minecraft wirklich ein Computerspiel ist bzw. ob Minecraft und alle anderen Spiele die mit dem Sandbox-Konzept funktionieren nicht sogar eine völlig neue Form von Spielen sind. Es gibt in Minecraft aktuell vier relevante Modi:

1. Der Überlebensmodus: Bei dieser Variante hat man nur begrenzte Ressourcen zur Verfügung und man muss sich zudem gegen Monster etc. wehren. Die eigene Lebensenergie kann schwinden, z. B. durch Angriffe von Monstern. Zudem muss man sich ernähren um bei Kräften zu bleiben. Auch die Ressourcen mit denen man Gebäude bauen kann sind begrenzt und müssen zudem gesammelt werden.

2. Der Hardcoremodus: Bei diesem Modus handelt es sich letztlich um eine besonders schwere Version des Überlebensmodus

3. Der Kreativmodus: Bei diesem Modus hat man unendliche viele Ressourcen und kann zudem nicht sterben. Man kann sich sogar fliegend bewegen. Es geht also nicht mehr darum zu kämpfen und mit den vorhandenen Ressourcen zu haushalten, sondern man kann sich ganz seiner Kreativität hingeben und die Welt von Minecraft verändern. Man kann auf diese Art und Weise seine eigene MinecraftWelt bauen und wenn man es möchte andere Spieler dazu einladen, sich in dieser Welt zu bewegen. Hierfür würde man einen eigenen Minecraft-Server einrichten.

4. Der Abenteuermodus: Dieser Modus hat ebenfalls eine gewisse Ähnlichkeit mit dem Überlebensmodus. Er ist speziell für den Fall vorgesehen, dass man einen 
eigenen Minecraft-Server besitzt und andere Spieler darauf einladen möchte. In manchen Fällen möchte man die Nutzungsmöglichkeiten der eingeladenen Spieler beschränken.

Minecraft ist aus vielen verschiedenen Gründen interessant. Da ist zum einen die Tatsache, dass wir es hier mit einem sehr erfolgreichen Spiel zu tun haben, welches hinsichtlich der Grafik und des Storytellings eher schwach ist. Die Darstellung des Spiels ist mehr als einfach gehalten, was es sehr vielen Menschen ermöglicht, auch mit verhältnismäßig einfachen technischen Ressourcen das Spiel zu spielen. Zum anderen wurde das Spiel auf sehr interessante Art und Weise vermarktet. Zu Beginn wurde eine Beta-version veröffentlicht, die man für einen geringen Betrag erwerben konnte. Auf diese Art und Weise verbreitete sich das Spiel rasant. Zudem wurde es von den Spielern intensiv in den Sozialen Medien kommuniziert und diskutiert. Zur Bekanntheit des Spiels trugen vor allem eine Vielzahl an Videos und Bildern bei, die zeigten, was die Spieler in Minecraft alles bauten.

Der Bereich Kreativität ist in Minecraft besonders ausgeprägt. Die Spieler nutzen die Plattform, um sowohl Phantasiegebilde als auch Nachbauten realer Gebäude zu erstellen. Dabei dauert mancher Bau viele Wochen und Monate ehe er fertig ist. Durch die technische Struktur des Spiels ist es zudem möglich, Minecraft auch in anderen Kontexten zu nutzen. So gibt es Bibliotheken wie die District Library in Ann Arbor, die einen eigenen Minecraft-Server aufgesetzt haben und diesen auch betreiben. In dieser Spielwelt werden die Spieler gebeten, die Stadt Ann Arbor nachzubauen. Wobei die Gebäude von außen möglichst wirklichkeitsgetreu nachempfunden werden sollen, während die Spieler die Nutzung also das innere der Gebäude frei gestalten können. Weitere Nutzungsmöglichkeiten insbesondere das von Kelvin Autenrieth entwickelte „Bibcraft“ beschreibe ich später in diesem Buch.

Minecraft ist mehr als nur ein Spiel. Es ist eine unglaublich kreative Welt. Erste Schulen benutzen Minecraft um z. B. im Kunstunterricht den Bau von historischen Sakralbauten zu lehren. Mit Minecraft können eine Vielzahl an Lehrinhalten spielerisch vermittelt werden. Dabei werden Lernen und Kreativität miteinander auf perfekte Art und Weise vernetzt.

In Minecraft entstehen immer wieder einzigartige Kunstwerke. In vielen Fällen stößt man auf diese Werke über Youtube-Videos.

Neben dem eigenen Spiel hat sich im Laufe der Jahre eine stetig wachsende Minecraft-Community gebildet. Die Spieler tauschen sich untereinander aus und gestalten zusammen neuen Minecraftwelten. Sie kümmern sich auch um den Aufbau von eigenen Informationssystemen wie z. B. Wikis um neues Wissen zu speichern und vor allem um es untereinander zu teilen.

\section{Social Games}

Social Games sind nicht etwas „soziale“ Games, die z. B. einen Fokus auf soziale Themen legen oder aber im Spiel soziale Aktionen erfordern. Bei dieser Gruppe handelt es sich um Spiele, die an die verschiedenen sozialen Netzwerke angedockt sind. Social Games sind vor allem auf Facebook zu finden. Das Grundmodell ist dabei verhältnismäßig einfach: Der Spieler beginnt ein Spiel, bei dem er verschiedene Aufgaben lösen muss. Die Anmeldung erfolgt über seinen Account bei Facebook und das Spiel selber findet auch auf der Plattform statt. Früher oder später ist es für den Spieler sinnvoll, andere Kontakte auf Facebook in das Spiel einzuladen damit sie bei der Lösung von Aufgaben helfen. Ein Beispiel: Vor ein paar Jahren spielte ich intensiv das 
Social Game „Mafia Wars“. Ein wesentlicher Bestandteil des Spiels ist der Aufbau einer eigenen Mafia. Mitglieder der eigenen Mafia können aber nur die Menschen werden, die mit mir auf Facebook verbunden sind. Um in diesem Spiel, erfolgreich zu sein ist es aber wichtig, eine möglichst große Mafia aufzubauen. Der Erfolg im Spiel ist also direkt abhängig von meiner Fähigkeit, andere Facebook-Kontakte zu aktivieren, ebenfalls mit zu spielen.

Natürlich gibt es auch Spiele, die keine Einbindung meiner Facebook-Kontakte erfordern. Spannend sind aber die Spiele, bei denen die Einbindung erfolgt. Viele der sogenannten Social Games sind nicht besonders komplex. Sie sind zudem so programmiert, dass man sie nur für fünf bis zehn Minuten spielen kann. Der zeitliche Aufwand ist also verhältnismäßig gering. Auf diesem Weg soll sichergestellt werden, dass die Spieler längerfristig spielen.

Man kann über den Sinn und Unsinn dieser Spiele geteilter Meinung sein. Klar ist aber, dass Sie die Entwicklung der sozialen Netzwerke insbesondere Facebook nachhaltig geprägt und angeschoben haben. Zudem sind es interessanterweise jene Spiele, die für einen offeneren Umgang mit Facebook und Co. sorgen - vorausgesetzt man möchte die Spiele mit einem hohen Anteil an Integration der eigenen FacebookKontakte spielen. Plattformen wie Facebook sind keine sozialen Communities. Sie sind vielmehr Plattformen auf denen sich tausende ja sogar Millionen kleiner Communities bewegen. In der Regel sind diese Plattformen Spiegelbilder unserer realen Kontakte. Vor allem jüngere Menschen nutzen Facebook und Co. um sich mit ihren Freunden in der analogen Welt zu vernetzen. Bei „Mafia Wars“ war ich irgendwann an meine Grenzen gestoßen, denn sehr viele meiner Facebook-Kontakte hatten kein Interesse an dem Spiel teilzunehmen. Ich brauchte aber unbedingt noch mehr Facebook-Freunde, die auch Interesse an dem Spiel hatten. Also wurde ich Mitglied in der verschiedenen Facebook-Gruppen des Spiels und vernetzte mich dort mit anderen Spielern des Spiels. Das bedeutet, wildfremde Menschen aus verschiedenen Ländern, die ich zudem nicht kannte wurden Teil meiner Facebook-Community. Sie müssen dies auf keinen Fall ebenfalls tun, aber das Beispiel zeigt, welche Möglichkeiten sich durch die Nutzung von Gaming in sozialen Netzwerken ergeben. Natürlich gibt es auch eine Vielzahl klassischer Games, die auf Plattformen wie Facebook gespielt werden. Außer der Tatsache, dass hier Facebook als Plattform agiert, gibt es aber keine weiterreichenden sozialen Vernetzungsaktivitäten.

Wie schon bei vielen anderen Games ist auch hier eine Bestandsarbeit nicht möglich. Auch die Nutzung in Veranstaltungen etc. ist schwierig, da diese Spiele immer an einen Account eines Mitglieds bei Facebook gebunden sind. Insofern eignen sich Social-Games nur äußerst begrenzt für die Nutzung in Bibliotheken.

\section{Casual Games}

Auch wenn es immer noch viele Menschen gibt, die mit dem Thema Gaming nichts anfangen können, es gibt weitaus mehr Gamer als man glauben mag. Viele Menschen wissen nicht, dass sie Gamer sind, denn sie spielen Computerspiele, die wir nicht als solche wahrnehmen. Wer würde auf die Idee kommen, dass „Solitair“, „Mahjong“ oder auch „Fruit Ninja“ richtige Spiele sind? Das Genre zu dem diese Spiele gehören nennt sich „Casual Games“. Übersetzt heißt dieser Begriff „Gelegenheitsspiele“. Es handelt sich zumeist um sehr einfache Spiele, die zudem keine hohen Anforderungen an die Hardware stellen. Es gibt sie zudem für verschiedene Plattformen. Die Spiele sind sehr einfach und somit kann man sie immer mal wieder für ein paar Minuten spielen um sich dann wieder anderen Dingen im Leben zu widmen. 


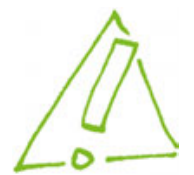

Nutzen Sie Spiele wie „Angry Birds“, in Ihren Tablet- und Smartphones-Schulungen. Des weiteren können Sie Events veranstalten, bei denen z. B. für die verschiedenen Level dieser Spiele gemeinsam Strategien entwickelt werden.
Wenn Sie das nächste Mal mit dem Bus oder der Bahn unterwegs sind, achten Sie einfach mal auf Ihre Mitreisenden. Sie werden feststellen, dass sehr viele Menschen auf ihrem Smartphone oder auf dem Tablet ein Spiel spielen.

Eines der bekanntesten und zugleich auch lustigsten Spiele der letzten Jahre ist sicherlich „Angry Birds“. Bei diesem Spiel geht es darum, dass ein paar Schweine einer Gruppe von Vögeln deren Eier gestohlen haben. Aus diesem Grund soll man nun den Vögeln helfen, diese Eier wieder zurück zu bekommen. Hierfür schießt man die Vögel mit einem Katapult auf die jeweiligen Bauten und Hindernisse der Schweine um diese und dabei die Schweine zu zerstören. Einige Vögel haben dabei besondere Fähigkeiten. In jedem Level findet der Spieler ein anderes Gebäude bzw. Objekt vor, in dem sich die Schweine verschanzt haben. Man hat nun eine begrenzte Anzahl an Vögeln die wie gesagt teilweise besondere Fähigkeiten haben, z. B. in dem sie sich im Flug wenn man sie antippt verdreifachen. Natürlich kann man sehen, wo die Schweine sind. Man muss also überlegen, wie man das Gebäude mit möglichst wenigen Vögeln zum Einsturz bringt.

Das Spiel macht sehr großen Spaß und ist für eine Vielzahl an Plattformen kostenlos oder aber für einen verhältnismäßig geringen Betrag erhältlich. Derartige Spiele sind sicherlich keine hochkomplexen Systeme. Sie sind aber weit verbreitet und schulen kontinuierlich die Nutzung verschiedener Controller wie z. B. die Computermaus oder einen Touchscreen. Nun mögen Sie einwenden, dass doch jeder Mensch in unserem Land wissen müsste, wie man eine Computermaus bewegt oder einen Touchscreen bedient aber dem ist nicht so. In unserer Gesellschaft wie auch in Bibliotheks-Teams können wir Menschen finden, die schon sehr weit im Umgang mit dem Computer und den digitalen Medien sind. Wir finden aber ebenso sehr viele Menschen, für die selbst einfachste Aufgaben am Computer oder dem Smartphone eine große Herausforderung darstellen. Hier können solche Casual-Games helfen, denn sie sind einfach genug, um sich nicht auf das Spiel als solches konzentrieren zu müssen.

Aber ich möchte nun nicht behaupten, dass es sich hierbei um Lernspiele handelt. Der wesentliche Punkt ist nachwievor der Spaß zwischendurch. Dieses Genre mag hinsichtlich der Nutzungsmöglichkeiten in Bibliotheken sowie für Schule und Bildung wenig relevant erscheinen. Es sorgt aber dafür, dass immer mehr Menschen Kontakt zum Thema Gaming haben. Als Bibliothek sollten Sie deshalb diese Spiele als ebenso relevant ansehen wie alle anderen Gaming-Bereiche.

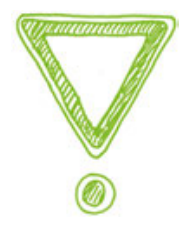

\section{Mobile Games}

Und jetzt nehmen wir die Spiele überall hin mit :-) Das mag komisch klingen aber genau darum geht es: „Mobile Games“. Ich habe über diese Spiele schon einiges geschrieben. Vor allem der Abschnitt zur Hardware und dort der Teil zu den mobilen Konsolen beinhaltet schon einiges. Mobile Games oder besser „Mobile Gaming“ stehen für eine logische Weiterentwicklung der Gaming-Welt. Ich meine damit weniger die Spiele, welche man auf dem Nintendo 3DS oder der Playstation Vita spielt, als vielmehr das Spielen auf Smartphones und Tablet-PCs wie z. B. dem iPad. 


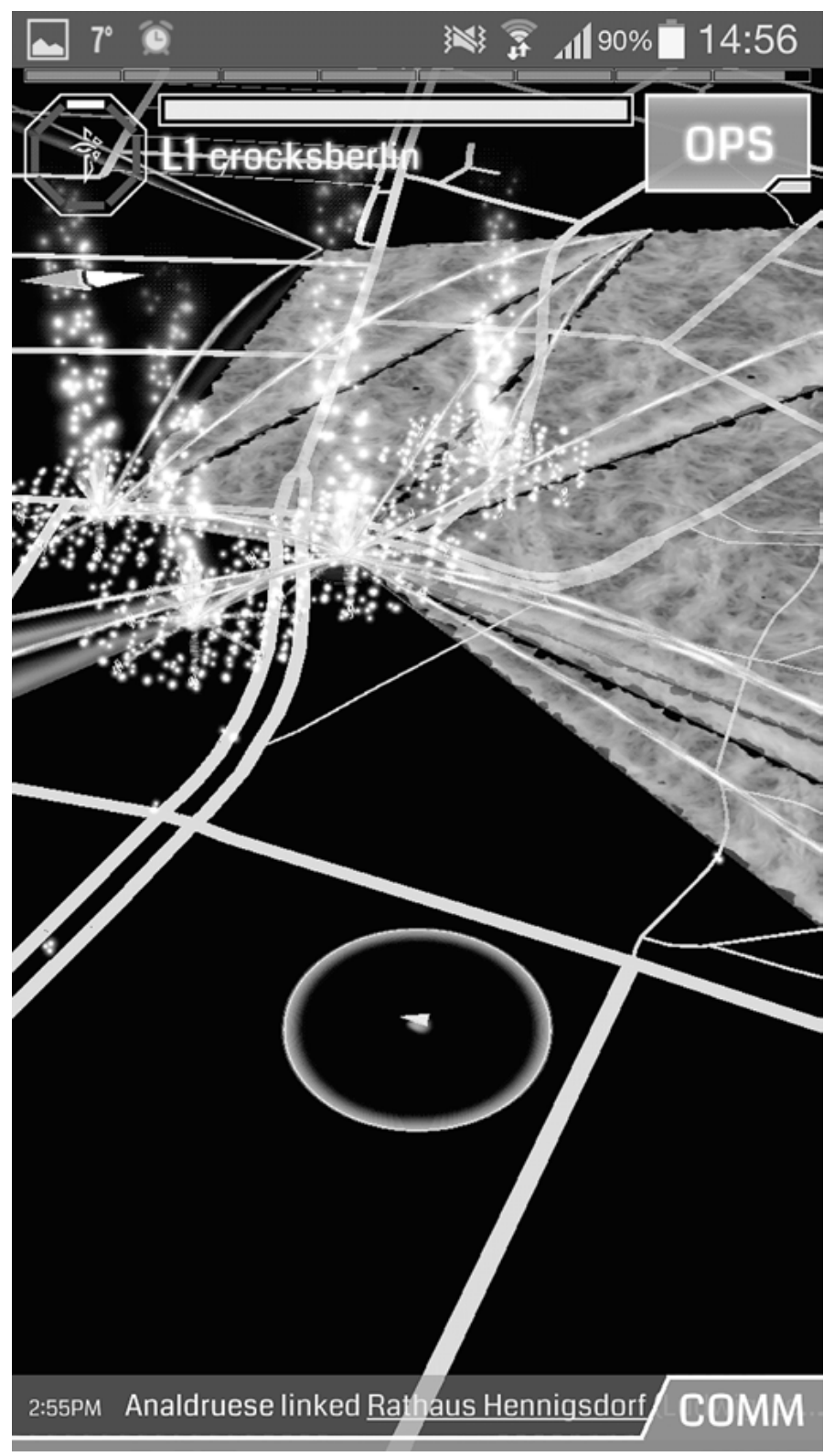

Abb. 20 Screenshot des Spiels Ingress

Das Spielen auf diesen Plattformen ist besonders interessant, denn es findet auf Devices statt, die ursprünglich nicht für Gaming konzipiert wurden, die aber gleichzeitig zu den zentralen Kommunikationsplattformen unserer Gesellschaft gehören. Schon beim klassischen Fernsehen waren die Games bei einem aufkommenden Massenmedium von Anfang an dabei. Auch bei den Handys und nun bei den Smartphones und Tablets spielen Games eine wesentliche Rolle. Grundsätzlich kann man zwischen zwei Spielformen unterscheiden:

1. Spiele die man auf dem Smartphone oder dem Tablet spielt, die aber „nur“ ein Spiel sind. Diese Spiele nutzen nicht die weiteren Nutzungsmöglichkeiten von Smartphones wie z. B. die Möglichkeit den Spieler zu orten oder die Kamera zu nutzen. In manchen Fällen handelt es sich dabei um Spiele, die für mobile Devices adaptiert wurden. Sehr viele dieser Spiele sind eher schwach. Selbst man- 
che Adaption eines sehr guten Retro-Games ist in der Version für Smartphones und/oder Tablets schwach und nicht empfehlenswert. Es gibt aber auch Ausnahmen wie z.B. die iPad-Version von „Deus Ex“.

2. Spiele die man auf dem Smartphone oder Tablet spielt, die aber die Nutzungsmöglichkeiten dieser besonderen Hardware nutzen. Dazu gehören z. B. die Möglichkeit der Ortung des Spielers oder aber die Nutzung von Kameras etc. Hier entwickelt sich gerade ein interessanter Markt, der viele neue Spielkonzepte hervorbringt. Manche Spiele wie z.B. „Ingress“ nutzen das Smartphone gar nur noch als Interface zwischen digitaler und analoger Welt. Bei diesem Spiel muss man, vereinfacht ausgedrückt, in der analogen Welt zu bestimmten Orten gehen und dort mit seinem Smartphone bestimmte Aufgaben erfüllen. So geht es in Ingress darum bestimmte Portale zu öffnen oder aber zu übernehmen. Die Portale befinden sich an realen Orten. Es handelt sich zumeist um Denkmäler, Kunstwerke oder besondere Gebäude. Der Spieler muss zu den realen Orten gehen. Das Spiel nutzt die Ortungsfunktion (GPS-Ortung) um festzustellen, ob man wirklich an dem Ort angekommen ist. Auf dem Bildschirm erscheint nun eine virtuelle Darstellung der Umgebung ohne die Gebäude aber erweitert um die im Spiel benannten Portale. Nun kann man mittels Touchscreen mit den virtuellen Portalen interagieren.

Mobile Games sind für Bibliotheken auf vielfältige Weise interessant. Klar ist, dass es keine Spiele sind, die man in den Bestand aufnehmen kann. Aber man kann mit Ihnen Arbeiten oder sogar Teil von ihnen werden. Bei vielen Mobile Games bieten sich Veranstaltungen an. So könnte man z. B. ein Rennwochenende durchführen, bei dem auf verschiedenen Plattformen inkl. den mobilen Systemen verschiedene Rennen gewonnen werden müssen. Man könnte auch spezielle Veranstaltungen nur für Mobile Games anbieten. Ebenso wichtig ist es aber, dass man wenn möglich Teil der Spiele wird. Jede Bibliothek sollte beispielsweise der Ort für ein Portal bei „Ingress“ sein. Und jede Bibliothek sollte auf Foursquare aktiv sein oder zumindest analysieren, wer der aktuelle Mayor der Bibliothek ist und was die User ansonsten über die Bibliothek schreiben. Sinnvoll wäre u.U.auch, ein „Special“ anzubieten.

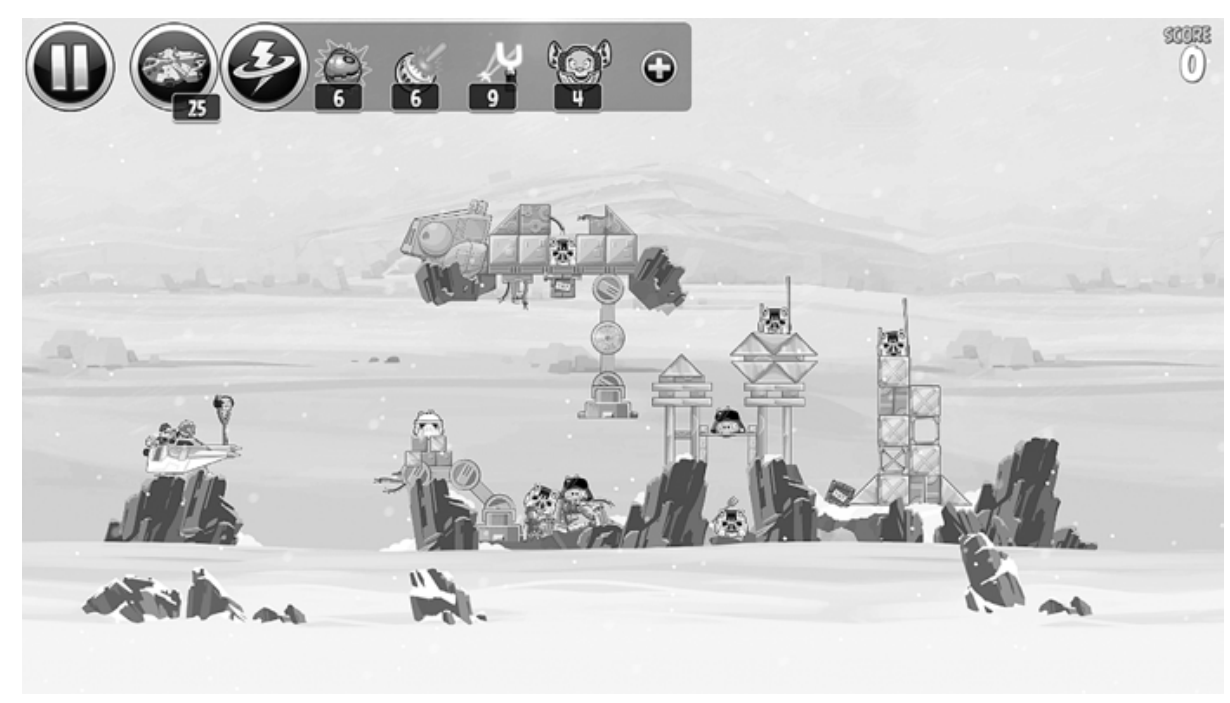

Abb. 21 Screenshot aus dem Spiel Angry Birds 


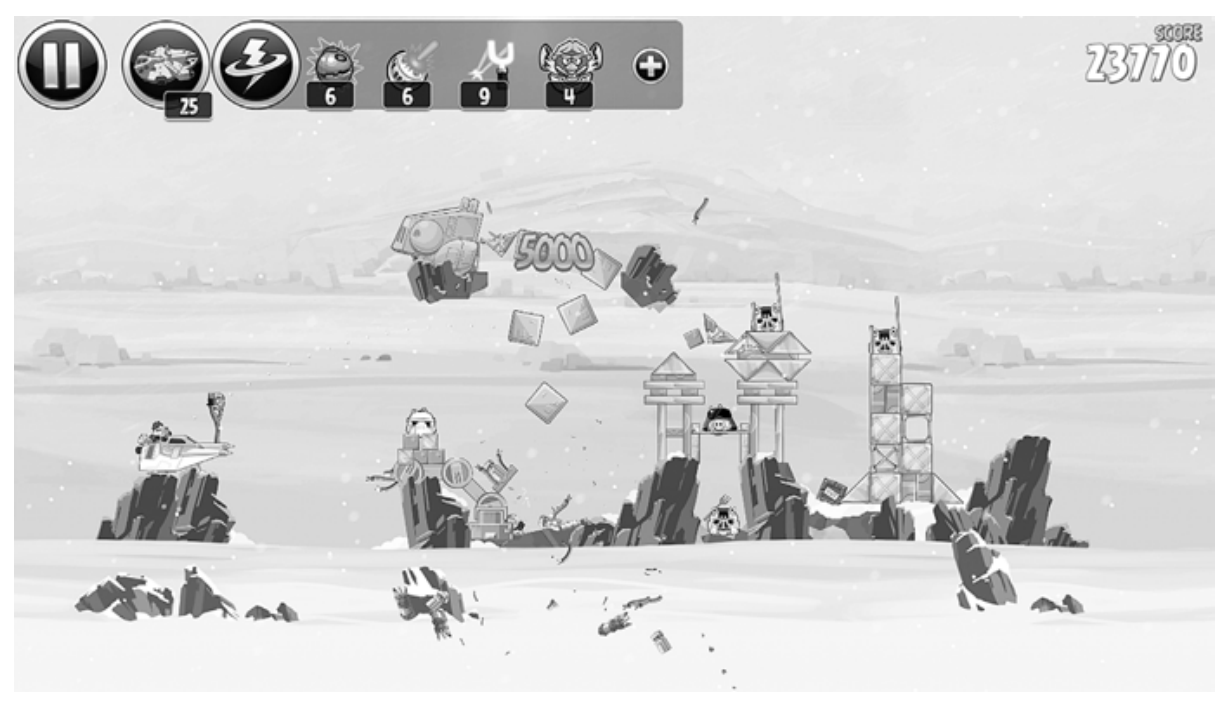

Abb. 22 Screenshot aus dem Spiel Angry Birds

\section{Indie-Games}

Das Thema Indie-Games ist sehr speziell und es lässt sich demnach auch nur schwer beschreiben bzw. definieren. Der Begriff steht für Spiele, die von kleinen und unabhängigen Entwicklern entwickelt und vertrieben werden. In den letzten Jahren haben sich neue digitale Vertriebsplattformen entwickelt, die es nun auch einzelnen Entwicklern ermöglichen Ihre Spiele zu vermarkten. Daraus resultierend ist ein riesiger und immer schwerer zu überschauender Markt entstanden. Täglich kommen neue Spiele hinzu und auch wenn die meisten dieser Spiele keinen Erfolg haben, gibt es immer wieder tolle Games, die sich dann einer immer größeren Fangemeinde erfreuen.

Ich selber spiele sehr gerne Indie-Games. Viele der großen Anbieter und Entwickler-Studios veröffentlichen kontinuierlich Mainstream-Spiele, die für den Massenmarkt bestimmt sind. Aber es sind die kleinen zumeist nur einer kleinen Gruppe bekannten Entwickler, die neue Wege gehen und dabei sehr oft einzigartige Kunstwerke erschaffen. Zudem sind viele dieser Spiele verhältnismäßig kurz. Das bedeutet, dass man manches Spiel in 30 Minuten durchgespielt hat. Sowohl das Gameplay als auch die Grafik, das Storytelling und natürlich die Musik überraschen immer wieder.

Für Bibliotheken ergeben sich gerade im Bereich der Indie-Games spannende Möglichkeiten. Natürlich ist es auch beinahe unmöglich, eine klassische Bestandsarbeit zu realisieren. Die Spiele werden zumeist nur digital z.B. über Plattformen wie „Humble Bundle“ vertrieben. Aber Bibliotheken können mit Indie-Entwicklern zusammenarbeiten bzw. eine Plattform sein. Eine solche Kooperation hilft beiden Seiten: Die Bibliothek bekommt neue Spiele, die während speziellen Gaming-Veranstaltungen gespielt werden können. Die Bibliothek kann dadurch Spiele nutzen, die weitab vom Mainstream sind und hat so ein besonderes Angebot. Die Entwickler wiederum haben die Möglichkeit, ihre Spiele einer breiten Öffentlichkeit vorzustellen. Es ist also vergleichbar mit Autorenlesungen bei denen die Bibliothek versucht, unbekannten Nachwuchsautoren eine Plattform zu bieten. 


\section{Altersfreigaben, Altersgruppen und die USK}

Ich weiß nicht ob Sie sich noch daran erinnern können, aber in regelmäßigen Abständen gibt es ein Anti-Gaming-Gewitter. Games werden als Killerspiele etc. bezeichnet. Verstehen Sie mich nicht falsch, ich finde Medienkritik wichtig und es gibt viele Dinge in der digitalen Welt inkl. des Themas Gaming, die man kritisch hinterfragen muss, aber die klassische Stigmatisierung von Games und Gamern ist lächerlich und erniedrigend. Dabei ist es wichtig, dass es wir uns auch mit den negativen Aspekten des Themas befassen. Für Bibliotheken ist diese Diskussion sehr wichtig, denn Sie werden in der Zukunft erklären müssen, warum Gaming für sie so wichtig ist, dass Sie dafür Zeit und Ressourcen verbrauchen. Es wird ebenso wichtig sein, dass Sie in der Lage sind, Eltern und Lehrer aber auch Gamer rudimentär zu beraten. Ein wichtiges Kriterium ist dabei die Altersfreigabe für Spiele. Es ist wichtig, dass Sie darauf achten, dass Kinder und Jugendliche nur diese Spiele bekommen, die sich hinsichtlich des Alters auch für sie eignen. Hierfür gibt es ein Klassifizierungssystem, welches Ihnen helfen soll, in diesem wichtigen Punkt keine Fehler zu machen. Ich rede von der USK.

Diese freiwillige und unabhängige Selbstkontrolle soll dafür sorgen, dass Kinder und Jugendliche nur die Spiele spielen können, die für Ihr Alter passend sind. Es geht dabei aber nur um die Frage, ob die Spiele für das jeweilige Alter unproblematisch sind oder nicht. Es geht also um eine Altersfreigabe, aber nicht um eine Aussage, ob das Spiel gut oder schlecht oder ob es gar pädagogisch wertvoll ist. Im Folgenden möchte ich kurz die einzelnen Einteilungen beschreiben:

1. USK 0: Diese Spiele sind für alle Altersklassen freigegeben. In der Diskussion um Gewaltdarstellungen in Computerspielen geht sehr oft unter, dass die meisten Spiele die auf den Markt kommen, diese Kennzeichnung haben.

2. USK 6: Diese Spiele sind für Menschen ab 6 Jahren freigegeben. Die Spiele sind komplexer und wenn es um Kämpfen geht, kann man die Spielelemente kaum mit der realen Welt verwechseln.

3. USK 12: Diese Spiele sind noch komplexer und eventuell kampfbetonter. Zudem sind die Darstellungen realistischer. Jedoch ist es immer noch so, dass es einen wahrnehmbaren Unterschied zwischen den Darstellungen im Spiel und der Realität gibt.

4. USK 16: Diese Spiele erfordern noch mehr Aktivitäten und erzeugen durch ihre Darstellungen und ihr Gameplay erhöhte Spannungszustände bei den Spielern.

5. USK 18: Diese Spiele haben keine Jugendfreigabe was bedeutet, dass Sie nur Erwachsenen zugänglich gemacht werden dürfen. Diese Spiele sind nicht nur sehr komplex, es sind vor allem Spiele mit teils sehr heftigen Gewaltdarstellungen.

Die USK ist ein spannendes und sehr wichtiges Instrument. Was mich besonders fasziniert ist die Tatsache, dass man bei der Bewertung der Spiele aktiv spielt. Es ist also keine Theoriediskussion.

Für Bibliotheken ist es wichtig, dass Sie sich nicht nur bezüglich der Bestandsarbeit mit dem Thema USK befassen. Sie sollten unbedingt in der Lage sein, die Freigaben an sich sowie die damit verbundene Prozedur der Prüfung verstanden haben und kommunizieren können. Gerade Eltern suchen sehr oft nach Rat. Ihnen muss zudem klar sein, dass diese USK-Freigaben nicht verhindern, dass Kinder und Jugendliche auch solche Spiele spielen, die für ihr Alter nicht freigegeben worden sind. Diese Spiele werden dann sehr oft von älteren Geschwistern oder den Eltern gekauft. Als Bibliothek wäre es wichtig, dass Sie Eltern informieren und helfen. Die USK ist kein 
„Spaßverein“ und die Freigaben werden zumeist lange diskutiert. Die Mitglieder der Prüfungskommission sind erfahrene Experten.

Das Wissen um die USK, die Bedeutung der Freigaben und das damit verbundene Prüfungsverfahren ist ein Thema mit dem Sie zudem Kompetenz beweisen können. Ich erlebe leider sehr oft, dass Bibliotheksmitarbeiter nur geringe Ahnung von diesem Themenbereich haben.

Denken Sie daran, dass die durch die USK erstellten Altersfreigaben auch für die Nutzung in der Bibliothek gelten. Dies gilt nicht nur für die Gamer sondern auch für alle Menschen, die beim Spielen zuschauen!

\section{Lernspiele}

In vielen Workshops und Gesprächen fragen Bibliotheken nach Lernspielen. Die Idee hinter dieser Frage ist die, dass man Spiele für etwas „vernünftiges“ nutzen möchte. Und in der Tat gibt eine Vielzahl an Anbietern solcher Lernspiele. Die Idee ist natürlich nicht schlecht. Wir wissen, das Gaming gleichbedeutend mit Lernen ist. Wir wissen auch, dass sehr viele Spiele eine Vielzahl an Fähigkeiten schulen, die wir auch in der Schule vermitteln möchten. Gaming bedeutet, das Verstehen von komplexen Systemen. Es bedeutet, dass ich mir eine mir unbekannte Welt erschließen muss. Ich muss herausfinden, was meine Aufgabe ist und wie ich die Aufgabe lösen kann. Ich muss die Regeln und Abläufe verstehen und ich muss daraus resultierend eine Strategie entwickeln. Diese wiederum muss ich ausprobieren und, wenn Sie nicht funktioniert, anpassen. Das ist aber längst noch nicht alles. In vielen Spielen muss ich mit anderen zusammenspielen. Hierfür muss ich mein eigenes Wissen teilen und mich mit anderen Spielern abstimmen. Darüber hinaus muss ich Sekundärinformationen erschließen und verstehen. All das ist nichts anderes als Lernen nur mit dem großen Unterschied, dass es freiwillig geschieht und es zudem einen riesengroßen Spaß macht. Wenn man dies alles so liest ist es mehr als nachvollziehbar, dass man Gaming „zum Lernen“ nutzen möchte. Und deshalb gibt es auch eine Vielzahl an Lernspielen.

Das Problem ist, dass die weitaus meisten dieser Lernspiele schlecht gemacht sind bzw. nicht funktionieren. Dies hat verschiedene Gründe. Der Hauptgrund ist der, dass sich viele dieser Spiele auf das Lernen und nicht auf das Spielen fokussieren. Sehr oft erkennt man bereits auf den ersten Blick, dass das Spiel aus Sicht eines Pädagogen und nicht aus Sicht eines Games-Entwicklers bzw. eines Gamers entwickelt wurde. Diese Spiele machen nur begrenzt Spaß und beim Gaming geht es nun mal primär um Spaß. Diese unterschiedlichen Ziele sorgen dafür, dass die weitaus meisten sogenannten Lernspiele wenig Erfolg haben. Natürlich kann man solche Spiele im Rahmen des Unterrichts nutzen. Dann wird aber aus dem freiwilligen Spiel ein Zwang, der zudem ein bestimmtes Lernziel verfolgt. Darüber hinaus sind viele der Lernspiele mit sehr kleinen Budgets entwickelt worden. Daraus resultiert immer wieder, dass sie an sich nicht konkurrenzfähig sind. Allerdings möchten Sie hier eine Zielgruppe erreichen, die auch in ihrer Freizeit Computerspiele spielt. Daraus resultiert eine gewisse Erwartungshaltung. Alle Spiele, die nicht dem aktuellen Standard entsprechen, werden es schwer haben. Ein guter Indikator ist, ob man das Spiel auch spielen würde, wenn man es nicht spielen muss.

Ich kann natürlich verstehen, dass viele Bibliotheken sehr gerne Lernspiele nutzen möchten, da man damit vermeindlich dem Bildungsauftrag entspricht und zudem nicht nur einfach nur Gaming anbietet. Viele Bibliotheken sehen Lernspiele als
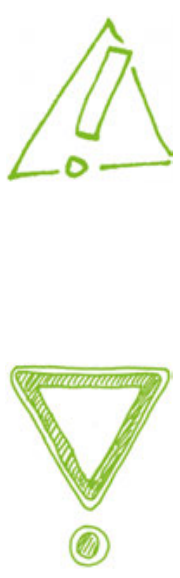
einen guten Kompromiss. Wenn Sie nun trotzdem unbedingt mit Lernspielen arbeiten möchten, sollten Sie auf ein paar wichtige Punkte achten:

1. Spielen Sie die Spiele an oder lassen Sie die Spiele von Gamern anspielen. Wenn diese die Spiele als nicht interessant definieren, sollten Sie vom Kauf der Spiele Abstand nehmen.

2. Achten Sie auf den Anbieter des Spiels. Ist es ein Games-Entwickler oder z. B. ein Schulbuch-Verlag? Hat das Unternehmen schon erfolgreiche Spiele veröffentlicht?

3. Wer möchte das Spiel nutzen? Gibt es bereits Lehrer, die Spiele im Unterricht nutzen möchten? Und haben diese Lehrer Erfahrung im Bereich Gaming?

4. Schaffen Sie ein Umfeld für Lernspiele. Wenn Lernspiele keinen Bezug zur Lebensrealität der Spieler haben werden Sie nur wenige Erfolg haben.

\section{Serious Games}

Serious Games werden sehr oft als Lernspiele definiert und in der Tat gibt es Überschneidungen zu den Lernspielen. Ich bin jedoch der Meinung, dass Serious Games eine eigene Gattung sind. Mit Serious Games sind nicht „seriöse“ Games gemeint. Es sind vielmehr angewandte Spiele, d.h. auch hier geht es nicht nur um das Spielen. Auch hier geht es um weitergehende Ziele. Es geht aber nicht darum, bestimmte Inhalte und Fakten über ein Spiel zu lernen. Es geht vielmehr darum vorhandenes Wissen anzuwenden um damit einen stärkeren Lerneffekt zu erzielen.

In vielen Fällen handelt es sich um Simulationen, in denen der Spieler bestimmte Situationen erleben und das bereits vorhandene Wissen anwenden soll. Das Wissen wird also angewandt. Serious Games ermöglichen beispielsweise das Durchspielen bestimmter Situationen, die man in der Realität so nicht ausprobieren kann. So gibt es Simulationen im Gesundheitsbereich, bei denen bestimmte Vorgänge in einem Operationssaal simuliert werden. In anderen Spielen werden die Spieler mit politischen Konfliktsituationen konfrontiert und sollen diese dann lösen.

Serious Games funktionieren vor allem dann, wenn Sie in ein dazugehöriges Lernumfeld aufgenommen werden. Es ist zudem von Vorteil, wenn es nach dem Spiel die Möglichkeit der Reflektion gibt.

Serious Games werden in der Zukunft auch für wissenschaftliche Bibliotheken interessant werden. In vielen Fächern lassen sich dadurch komplexe Lehrinhalte spielerisch vermitteln Dazu gehören u.a. die Wirtschaftswissenschaften, Naturwissenschaften, Politologie, Soziologie, Pädagogik, Marketing und Architektur.

Öffentliche Bibliotheken könnten mit Lehrern Lernnetzwerke aufbauen, in denen sie gemeinsam ausgewählte Serious Games nutzen und sich somit als Lernort positionieren können. Ansonsten ist es auch hier wichtig, sich sowohl die Spiele als auch die Anbieter der Spiele ganz genau anzusehen.

\section{Und noch mehr Gaming}

Spielen ist nicht erst im Computerzeitalter erfunden worden. Mit den neuen Kommunikations- und Medientechnologien ist Gaming weiter entwickelt worden. Heute können tausende Menschen vernetzt und im selben Moment und dabei an unterschiedlichen Orten gemeinsam das gleiche Spiel spielen. Und die Technologie ermöglicht es uns zudem, Phantasiewelten zu schaffen die weit über das hinausgehen, was unser Gehirn zu denken vermag. Aber Spielen an sich, das Ausprobieren, das Schlüpfen in andere Rollen, das Erträumen anderer Orte, all das und noch viel mehr ist Teil unse- 
res menschlichen Seins. Nicht die Verwaltungsvorschriften und Hierarchien sondern das spielerische Lernen und Denken macht uns zu kreativen Wesen. Und so ist Gaming mit Sicherheit eine der ältesten Handlungen unserer Spezies.

Auf den letzten Seiten haben Sie eine Vielzahl an unterschiedlichen Genres und Definitionen im Bereich Gaming kennengelernt. Aber Gaming ist weitaus mehr als „nur“ ein paar Games. Gaming entwickelt sich weiter und es beginnt andere Bereiche unserer Gesellschaft bzw. unserer Realität zu verändern. Wenn man sich mit dem Thema als Ganzes auseinandersetzen möchte, dann muss man auch die Bereiche verstehen, in denen Gaming in anderen Kontexten angewendet wird. Stellen Sie sich einfach vor, Gaming wäre nicht mehr an die jeweilige Software gebunden. Die mit dem Spielen verbundenen Denk- und Arbeitsweisen und die Gaming-Kultur sind nämlich nicht abhängig von irgendeiner Soft- und Hardware. Sie können auch in anderen Bereichen angewandt werden und unsere Welt verändern.

Im Folgenden möchte ich zwei Phänomene beschreiben, bei denen dies der Fall ist:

\section{Gamification}

Gamification rules the world! Das mag vielleicht etwas überdreht klingen aber es stimmt. Gamification ist ein Thema, welches global diskutiert und erfolgreich angewendet wird. Die Grundidee ist verhältnismäßig einfach. Ursprünglich bedeutete Gamification die Übernahme von Gaming- bzw. Spielelementen in Web-Anwendungen. Wie ich bereits des Öfteren geschrieben habe, sind Games auf der einen Seite komplexe Systeme und Gaming bedeutet vor allem Lernen und Arbeiten. Viele Gamer sind bereit Zeit und Energie zu investieren, um sich mit Sekundärinformationen zu versorgen bzw. diese zu erstellen, zu erschließen und zu vermitteln. Warum machen diese Menschen das? Die Antwort ist letztlich einfach: Sie werden durch die Spiele und die Gaming-Kultur motiviert. Sie bekommen klare Regeln und haben doch genug Freiraum für eigene Ideen. Sie bekommen Ziele und ein Feedback und sie dürfen Ideen und Strategien ausprobieren. Und natürlich handelt es sich sehr oft um einen Wettbewerb. Was also liegt näher, als diese Systematik in andere Webanwendungen zu implementieren? Genau das tut Gamification. Ein einfaches und immer wieder gern genutztes Beispiel ist die App „Foursquare“. Diese App nutzt die Möglichkeit aus, dass Sie mit Ihrem Smartphone geortet werden können. Wenn Sie die App starten, können Sie angeben, was sich an dem Ort befindet an dem Sie sich gerade aufhalten. Hat jemand den Ort bzw. das Gebäude oder ähnliches bereits eingegeben, können Sie an dem Ort „einchecken“. Das bedeutet, Sie informieren Ihre Kontakte auf Foursquare, wo Sie gerade sind. Sie können dabei auch einen eigenen Text eingeben. Zusätzlich kann diese Information auch über Twitter und Facebook verteilt werden. Schließlich ist es möglich, für die einzelnen Orte Tipps zu hinterlassen. Auch Fotos vom jeweiligen Ort können aufgenommen und online geteilt werden.

Durch die Aktivitäten der Nutzer entsteht eine nutzerbasierte Datenbank. Die Menschen, die hier Tipps z. B. für ein Gericht in einem Restaurant geben, waren wirklich dort, was die Quelle der Information auf jeden Fall vertrauenswürdiger macht.

Nun stellt sich natürlich die Frage, warum die Menschen bereit sind, kostenlos Ihre Daten in die Datenbank einzugeben und zudem Informationen über ihren jeweiligen Aufenthaltsort auf Twitter oder Facebook zu teilen. Die Antwort darauf ist ganz einfach: weil es ein Spiel ist. Genauer gesagt ist es eine Gamification-Anwendung. Der User bekommt für jedes Einchecken Punkte und er steht im Wettbewerb zu seinen Kontakten auf Foursquare. Zudem kann man sogenannte Badges freischalten. Es gibt z.B. das „Bookworm-Badge“ (Bücherwurm-Badge) wenn man in einer bestimmten Anzahl an Bibliotheken eingecheckt hat. 


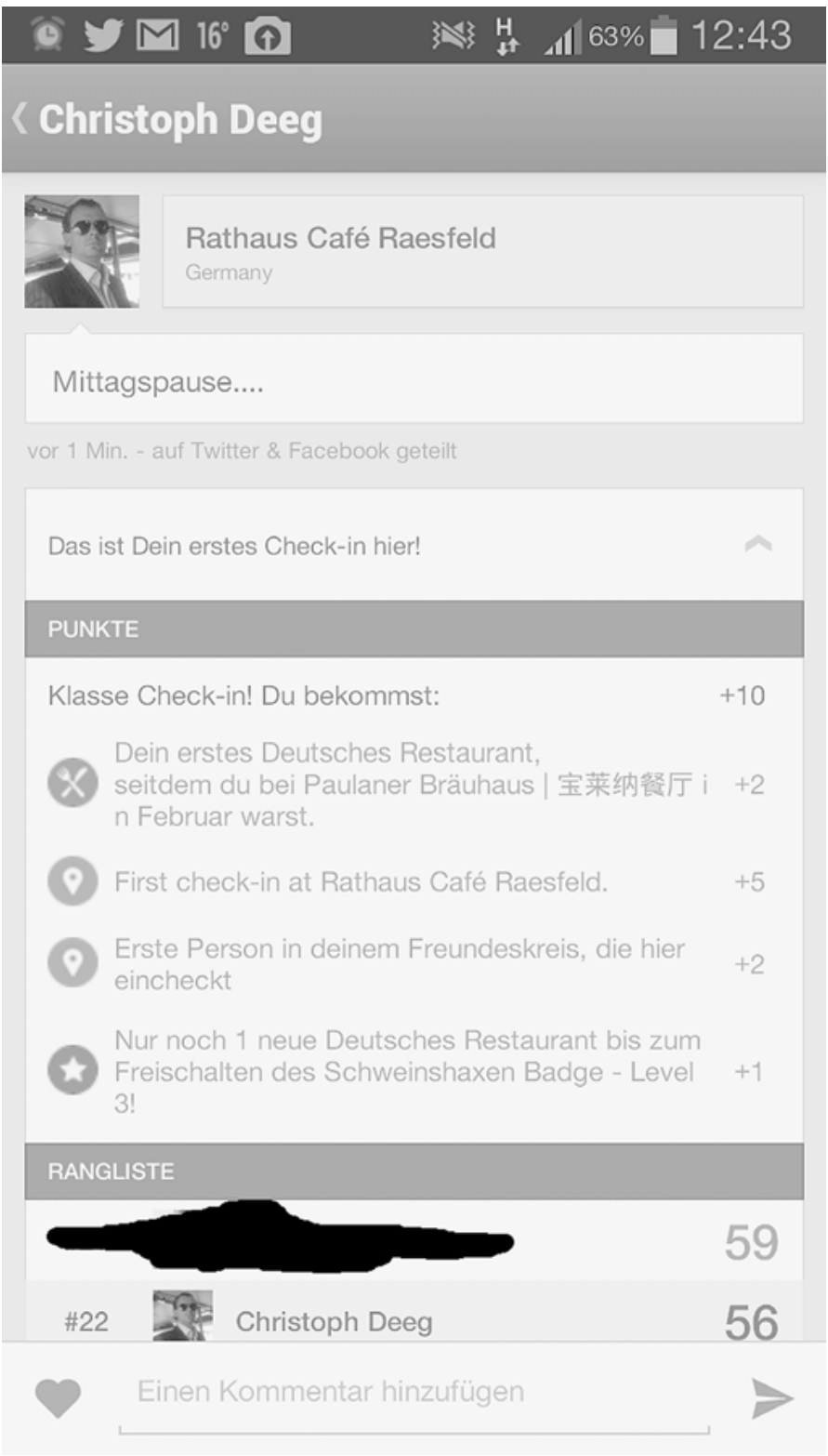

Abb. 23 Screenshot der App Foursquare

Wie gesagt, Foursquare ist nur ein kleines Beispiel und es zeigt zwar die Nutzung aber weniger das Potential von Gamification-Anwendungen. Aber Gamification an sich hat bereits Einzug in viele Unternehmen gehalten. So geht man davon aus, dass in wenigen Jahren 50-60 \% aller Innovationsmanagement-Prozesse in Unternehmen auf Gamification basieren werden, Gamification hilft beim Lernen, bei der Arbeit und in vielen weiteren Bereichen unseres Lebens. Man könnte auch sagen, es gibt wahrscheinlich keinen Bereich in dem Gamification nicht angewendet werden könnte. Dies betrifft auch und insbesondere Bibliotheken. Stellen Sie sich vor, ein OPAC würde wie ein Game funktionieren? Stellen Sie sich vor, der OPAC würde den Nutzer spielerisch trainieren und sich an die jeweiligen Bedürfnisse des Nutzers anpassen können? Gleiches gilt für die Anwendung von Datenbanken.

Allerdings ist die Entwicklung von Gamification-Anwendungen nicht einfach und es funktioniert auch nicht bei jedem Menschen. Besonders wichtig ist, dass die Anwendung 
einen Bezug zur Lebensrealität der Person hat, die mit dem Angebot arbeitet. Foursquare z. B. ist insofern Teil der Lebensrealität von Menschen, als dass diese Menschen unterwegs sind und sich erst dadurch an verschiedenen Orten einchecken können.

Das klingt sicherlich sehr einfach. Es ist es aber nicht. Gamification bedeutet nicht, dass man einfach nur ein paar Punkte auf Aufgaben verteilt und mit Badges und Wettbewerb hantiert. Gamification funktioniert nur dann, wenn Sie ein passendes und umfassendes Gamification-Konzept bzw. eine funktionierende Gaming-Mechanik haben, welche auf Ihre Zielgruppe passt. Es ist zudem auch hier notwendig, dass Sie für ein passendes Umfeld sorgen.

\section{Alternate Reality Games}

Alternate Reality Games sind eine Weiterentwicklung des klassischen Gaming. Alternate Reality Games erschaffen eine Spielwelt, indem sie verschiedene Medien und die Realität miteinander verschmelzen lassen. Das Spiel nutzt alle möglichen Kommunikationsmedien wie eMails, Social Media-Plattformen wie z. B. Blogs oder Twitter, Telefon etc. Darüber hinaus werden reale Orte in das Spiel eingebunden. In manchen Fällen werden auch an realen Orten fiktive Geschichten erzählt. So kann man eine Figur aus dem Spiel plötzlich in der Realität erleben, wie sich z.B. mit jemandem streitet. Alternate Reality Games lassen die Grenze zwischen Fiktion und Realität verschwimmen. Sie werden Teil unseres Umfeldes. Diese Einbindung unserer Lebensrealität ermöglicht völlig neue Spielerfahrungen. Allerdings sind komplexe Spiele aus diesem Genre sehr aufwendig. Vor allem die Werbeindustrie experimentiert mit diesen Modellen. So werden bestimmte Filme oder Computerspiele aber auch Bücher (Romane) auf diesem Weg vermarktet oder auch begonnen, d.h. das Spiel ist quasi der erste Teil des Buches. Alternate Reality Games sind vor allem spannende Ansätze um Geschichten zu erzählen. Der Unterschied zum Lesen eines Buches oder zum Sehen eines Films ist der, dass der „Spieler“ Teil der Geschichte wird. Er erlebt die Geschichte hautnah mit und erlebt sie so intensiver. In manchen ARG's ist noch nicht einmal bekannt, wann bzw. wo das Spiel anfängt.

Für Bibliotheken sind Alternate Reality Games ein spannendes Genre. Sie benötigen keine spezielle Hardware, sondern können die vorhandenen Medientechnologien und vor allem das Gebäude der Bibliothek als Teil des Spiels nutzen. Natürlich ist das Entwickeln eines solchen Spiels nicht einfach und wahrscheinlich werden Sie externe Hilfe benötigen. Auf der anderen Seite können Sie damit aber sowohl Jugendliche als auch Erwachsene begeistern. Wenn Sie in diesem Bereich aktiv sein wollen, brauchen Sie aber nicht nur Know-How bezüglich des Erzählens von Geschichten und der Entwicklung eines solchen Games. Sie benötigen ebenso fundiertes Wissen in der Nutzung moderner Kommunikations- und Medientechnologien.

Sie haben nun weitere verschiedene Gaming-Formen kennengelernt. Jedes der beschriebenen Genres und jede Variante bzw. Anwendung ist spannend und könnte auf die eine oder andere Art und Weise in die Bibliotheksarbeit einfließen. Und zu jedem der genannten Themen könnte man ein ganzes Buch verfassen. Und zum Glück gibt es diese Bücher auch. Wichtiger als das Lesen von Büchern ist aber das Vernetzen mit Gamern und Games-Entwicklern. Ich habe die Gruppe „games4culture“ auf Facebook schon angesprochen. Neben Mitarbeitern aus Bibliotheken, Museen und Archiven finden Sie hier auch weitere Experten zu allen von mir beschriebenen Formaten und Genres. Kommen Sie einfach in die Gruppe und stellen Sie Ihre Fragen. Sie werden garantiert Hilfe bekommen. Gerade in der Anfangsphase ist es wichtig, dass Sie sich vernetzen und lernen. 